\title{
CDK5-induced p-PPAR $\gamma($ Ser 112) downregulates GFAP via PPREs in developing rat brain: effect of metal mixture and troglitazone in astrocytes
}

\author{
A Rai $^{1,6}$, S Tripathi ${ }^{1,5}$, R Kushwaha ${ }^{1,2,5}$, P Singh ${ }^{3}$, P Srivastava ${ }^{3}$, S Sanyal ${ }^{4}$ and S Bandyopadhyay ${ }^{\star 1,1,2,6}$
}

The peroxisome proliferator-activated receptor gamma (PPAR $\gamma$ ), a group of ligand-activated transcriptional factors, is expressed in glial fibrillary acidic protein (GFAP)-immunoreactive astrocytes. Here, we investigated the role of PPAR $\gamma$ in regulating GFAP using a mixture of $\mathrm{As}, \mathrm{Cd}$ and $\mathrm{Pb}$ (metal mixture, $\mathrm{MM}$ ) that induces apoptosis and aberrant morphology in rat brain astrocytes. We observed a phospho PPAR $\gamma$ (serine 112 (S112)) (p-PPAR $\gamma$ (S112))-mediated downregulation of GFAP in the MM-exposed astrocytes. We validated this using pure PPAR $\gamma$ agonist, troglitazone (TZ). As reported with MM, TZ induced astrocyte damage owing to reduced GFAP. In silico analysis in the non-coding region of GFAP gene revealed two PPAR $\gamma$ response elements (PPREs); inverted repeat 10 and direct repeat 1 sequences. Gel shift and chromatin immunoprecipitation assays demonstrated enhancement in binding of p-PPAR $\gamma$ (S112) to the sequences, and luciferase reporter assay revealed strong repression of GFAP via PPREs, in response to both MM and TZ. This indicated that suppression in GFAP indeed occurs through direct regulation of these elements by p-PPAR $\gamma$ (S112). Signaling studies proved that MM, as well as TZ, activated the cyclin-dependent kinase 5 (CDK5) and enhanced its interaction with PPAR $\gamma$ resulting into increased p-PPAR $\gamma$ (S112). The p-CDK5 levels were dependent on proximal activation of extracellular signal-regulated protein kinase $1 / 2$ and downstream Jun N-terminal kinase. Taken together, these results are the first to delineate downregulation of GFAP through genomic and non-genomic signaling of PPAR $\gamma$. It also brings forth a resemblance of TZ with MM in terms of astrocyte disarray in developing brain.

Cell Death and Disease (2014) 5, e1033; doi:10.1038/cddis.2013.514; published online 30 January 2014

Subject Category: Neuroscience

Glial fibrillary acidic protein (GFAP) is the major intermediate filament protein that constitutes a major part of the astrocyte cytoskeleton. ${ }^{1}$ Enhanced expression of GFAP causes reactive gliosis ${ }^{2}$ that induces brain injury and degeneration. ${ }^{3}$ Nonetheless, GFAP preserves shape and arbor of astrocyte processes contributing to mechanical strength of the cell. ${ }^{1}$ Deregulation of GFAP leads to anomalies in developing and adult brain, engendering severe psychiatric disorders, ${ }^{4}$ rare genetic diseases ${ }^{5,6}$ and encephalopathy. ${ }^{7,8}$

The peroxisome proliferator-activated receptor (PPAR) group of ligand-activated transcription factors influence metabolism and functions of astrocytes in brain. ${ }^{9,10}$ The PPAR gamma (PPAR $\gamma$ ) promotes apoptosis ${ }^{11}$ and participates in differentiation of astrocytes. ${ }^{12}$ However, the role of PPAR $\gamma$ in GFAP regulation is unexplored.

The classical ligand-dependent activation of PPAR $\gamma^{13}$ involves recruiting co-activators/cofactors and binding to cognate DNA-responsive element (PPAR $\gamma$ response elements, PPREs), either 'direct' or 'inverted' repeat type, on the promoter region of target genes. ${ }^{13,14}$ Being a phosphoprotein, activity of PPAR $\gamma$ is affected by phosphorylation status. ${ }^{15,16}$ The serine 112 (S112) residue of PPAR $\gamma$ is often hyperphosphorylated by growth factors and stress as a crucial post-translational event. ${ }^{17}$

Activation of cyclin-dependent kinase 5 (CDK5) is reported to increase phosphorylation of PPAR $\gamma$ in pancreatic $\beta$-cells, ${ }^{18}$ human embryonic kidney cells, ${ }^{19}$ colon cancer cells ${ }^{20}$ and adipose tissue. $^{21}$ The CDK5 and mitogen-activated protein kinases (MAPKs) are associated with cytoskeletal proteins in rat brain, ${ }^{22}$ and cross talk between CDK5 and extracellular signal-regulated protein kinase $1 / 2$ (ERK1/2) moderates neuroplasticity ${ }^{23,24}$ and regulates glial migration. ${ }^{25}$ However, the interdependence of these kinases in regulating GFAP is unreported.

We reported earlier that a mixture of $\mathrm{As}, \mathrm{Cd}$ and $\mathrm{Pb}$ (metal mixture (MM)), at doses relevant to human exposure, attenuated GFAP levels, adversely affected astrocyte morphology and induced apoptosis in developing rat brain. ${ }^{26}$

\footnotetext{
${ }^{1}$ Developmental Toxicology, Council of Scientific and Industrial Research-Indian Institute of Toxicology Research (CSIR-IITR), Lucknow 226001, India; ${ }^{2}$ Academy of Scientific and Innovative Research, Lucknow 226001, India; ${ }^{3}$ Department of Biochemical Engineering \& Biotechnology, Indian Institute of Technology, New Delhi 110016, India and ${ }^{4}$ DTDD Division, CSIR-Central Drug Research Institute, Lucknow 226031, India

${ }^{*}$ Corresponding author: S Bandyopadhyay, Developmental Toxicology, Council of Scientific and Industrial Research-Indian Institute of Toxicology Research (CSIR-IITR), MG Road, Lucknow 226001, India. Tel: +91 522 2613786, 2627586; Fax: +91 522 2628227; E-mail: sanghmitra @iitr.res.in

${ }^{5}$ These authors contributed equally to this work.

${ }^{6}$ Co-corresponding authors.

Keywords: PPAR $\gamma$; phosphorylation; downregulate; GFAP; kinase activation

Abbreviations: TZ, troglitazone; MM, metal mixture; PPREs, peroxisome proliferator responsive element; p-PPAR $\gamma$, Phospho-peroxisome proliferator-activated receptor gamma; GFAP, glial fibrillary acidic protein; CDK5, cyclin-dependent kinase5; EMSA, electrophoretic mobility shift assay; ChIP, chromatin immunoprecipitation; qPCR, quantitative PCR; PBS, phosphate-buffered saline; SDS, sodium dodecyl sulfate; TBST, Tris-buffered saline and Tween 20; PCR, polymerase chain reaction Received 03.8.13; revised 16.11.13; accepted 20.11.13; Edited by A Verkhratsky
} 


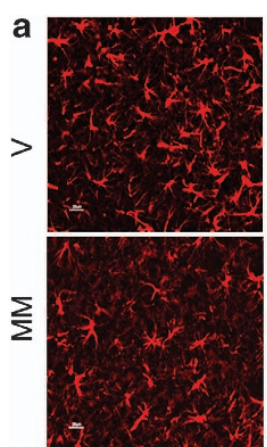

GFAP

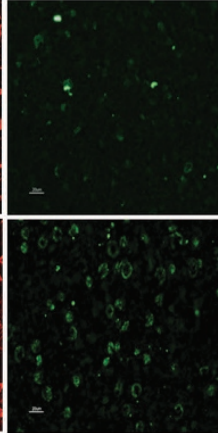

p-PPARY

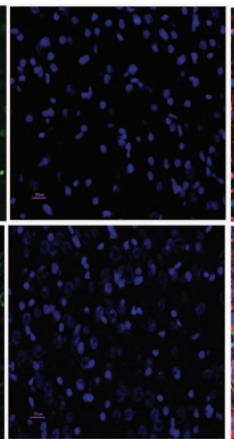

HOECHST

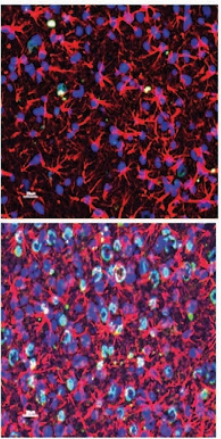

MERGED

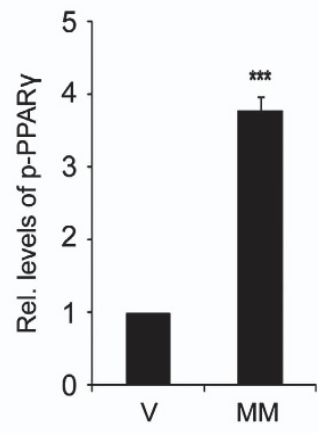

b

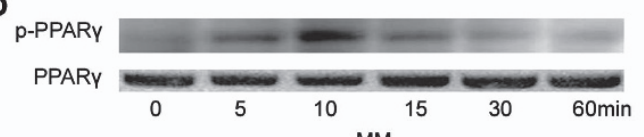

C
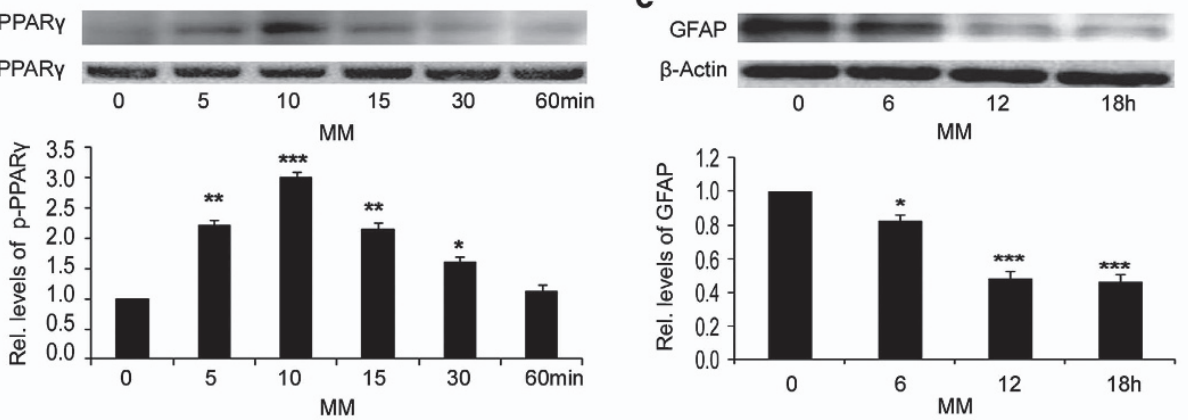

d

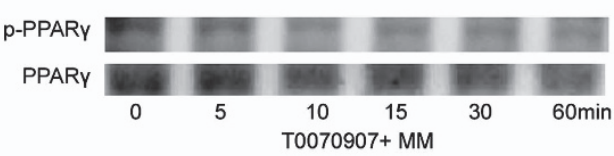

e
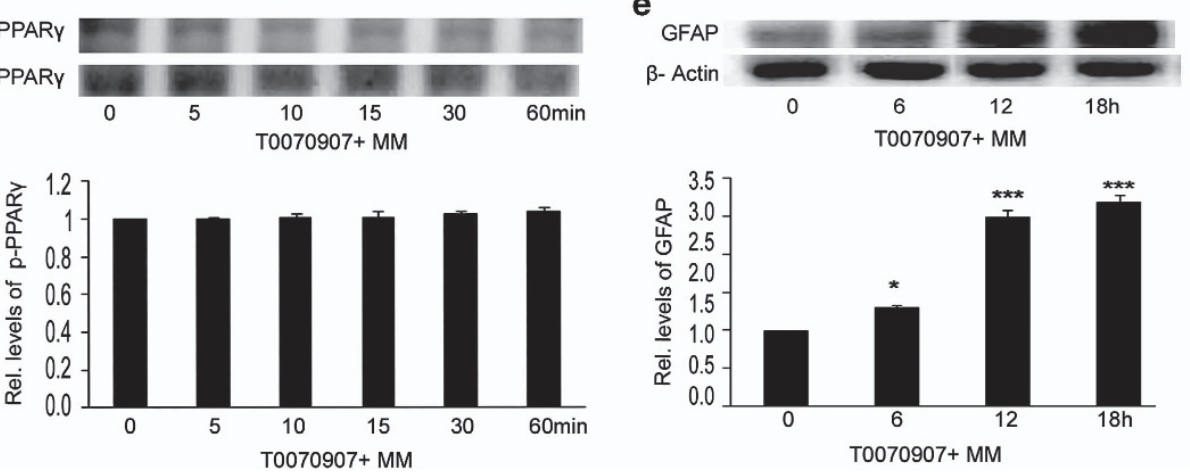

Figure 1 MM stimulates p-PPAR $\gamma($ S112) that downregulates GFAP in rat brain astrocytes. (a) Five- $\mu$ m-thick cryostat sections of cerebral cortex (coronal section) from vehicle (V)- and MM-treated rats were co-labeled for GFAP, p-PPAR $\gamma$ (S112) and nuclear Hoechst. LHS: Representative photomicrograph ( $\times 20$ magnification) of GFAP (red fluorescence), p-PPAR $\gamma$ (S112) (green fluorescence) and nucleus (blue fluorescence), and the three merged in the same field. RHS: The p-PPAR $\gamma$ (S112)/GFAP ratio normalized with nuclear Hoechst. Sections are representatives of four rats from four different litters, and bar diagrams represent mean $\pm S$.E. ${ }^{* * *} P<0.001$ (compared with V). Rat primary astrocytes were pre-incubated in reduced serum medium, or T0070907 in reduced serum medium for 60 min, and co-treated with MM for the indicated time points. (b) Representative western blot (upper panel) and densitometry (lower panel) of p-PPAR $\gamma$ (S112) relative to PPAR $\gamma$ in MM-treated astrocytes. Data represent mean \pm S.E. of four independent experiments in triplicate. ${ }^{* \star} P<0.001$, ${ }^{* \star} P<0.01$ and ${ }^{*} P<0.05$ (compared with $0 \mathrm{~min}$ ). (c) Representative western blot (upper panel) and densitometry (lower panel) of GFAP relative to $\beta$-actin in MM-treated astrocytes. Data represent mean \pm S.E. of four independent experiments in triplicate. ${ }^{* \star \star} P<0.001$ and ${ }^{\star} P<0.05$ (compared with $\mathrm{Oh}$ ). (d) Representative western blot (upper panel) and densitometry (lower panel) of p-PPAR (S112) relative to PPAR $\gamma$ at indicated time points in T0070907+MM-treated astrocytes. Data represent mean \pm S.E. of four independent experiments in triplicate. (e) Representative western blot (upper panel) and densitometry (lower panel) of GFAP relative to $\beta$-actin at indicated time points in T0070907 + MM-treated astrocytes. Data represent mean \pm S.E. of four independent experiments in triplicate. ${ }^{* \star} P<0.001$ and ${ }^{\star} P<0.05$ (compared with $0 \mathrm{~h}$ )

The synergistic effect on astrocytes involved initial activation of ERK1/2 that in turn stimulated Jun N-terminal kinase (JNK) signaling. ${ }^{26}$ Here, we used MM-exposed rats to understand the GFAP-regulating role of phospho-PPAR $\gamma$ (p-PPAR $\gamma$; S112) in astrocytes.

To validate the mechanism of GFAP regulation, we used the PPAR $\gamma$ agonist troglitazone (TZ) that is known to influence the metabolic state of astrocytes. ${ }^{27} \mathrm{TZ}$ modified astroglial glucose metabolism and mitochondrial function, and proved to be beneficial in neurodegenerative conditions. ${ }^{28}$
However, TZ-mediated neuroprotection by astrocyte-specific mechanisms was non-genomic and not through PPAR $\gamma$ activation. ${ }^{28,29}$ Here, we explored whether TZ had any GFAP-modulating role by the genomic action of PPAR $\gamma$.

We investigated the phosphorylation of PPAR $\gamma$ at $\mathrm{S} 112$ residue, and probed binding of $\operatorname{PPAR} \gamma(\mathrm{S} 112)$ to functional PPREs in GFAP gene in MM- and TZ-exposed astrocytes. We verified whether CDK5 had any major role in phosphorylation of PPAR $\gamma$. We focused on activations of ERK $1 / 2$ and JNK pathways that may culminate in altered astrocyte properties. 
The importance of our findings is twofold, as they provide the molecular mechanism governing GFAP modulation by PPAR $\gamma$ and point to the deregulation of astrocytes by $\mathrm{TZ}$.

\section{Results}

Effect of MM on levels of p-PPAR $\gamma$ and effect of p-PPAR $\gamma$ on GFAP in rat brain astrocytes. We reported earlier that MM damaged developing astrocytes in rat brain, where GFAP levels attenuated, resulting in altered astrocyte morphology. ${ }^{26}$ Here, we investigated a probable mechanism that modulates GFAP expression in astrocytes. We treated the developing rats (in vivo) and cultured astrocytes (in vitro) with MM. We observed an increase in p-PPAR $\gamma$ (S112) both in vivo (Figure 1a) and in vitro (Figure 1b). To identify whether this upregulated p-PPAR $\gamma$ (S112) suppresses GFAP (Figure 1c), we pre-incubated MM-treated cultured astrocytes with a PPAR $\gamma$ antagonist, T0070907. T0070907 prevented the rise in p-PPAR $\gamma$ (S112) (Figure 1d) and fall in GFAP (Figure 1e).

a
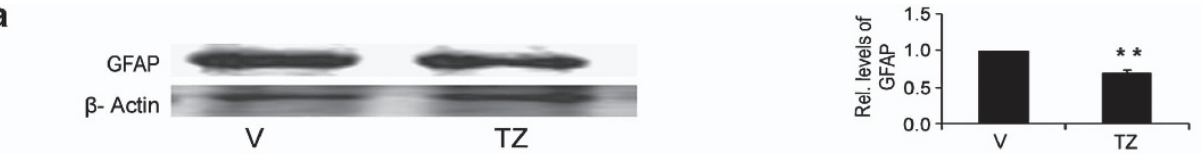

b
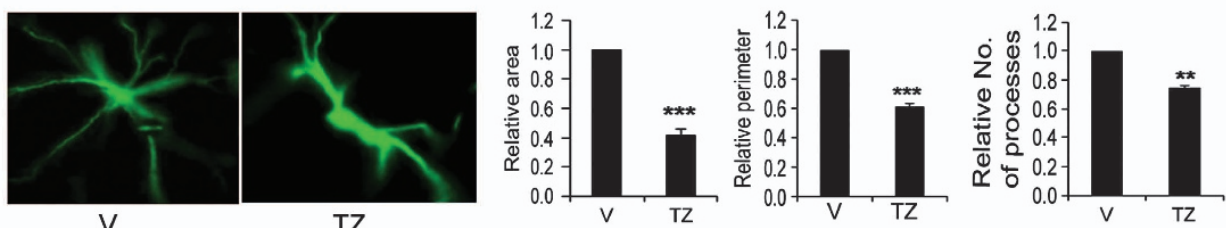

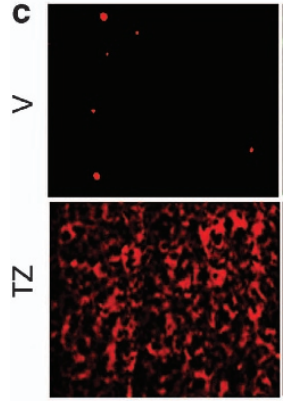

p-PPARy

d

$$
\text { G-Actin }
$$

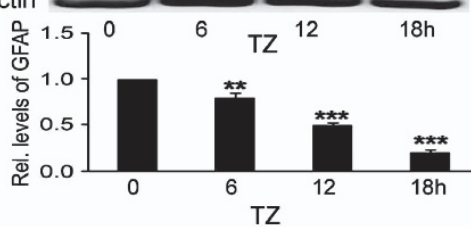

f GFAP $\beta$-Actin
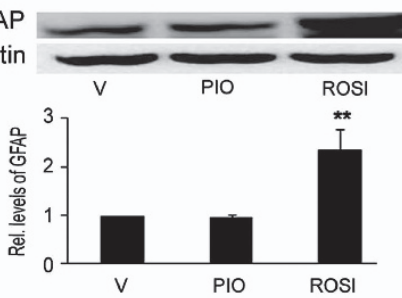

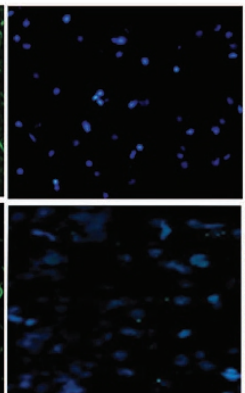

HOECHST
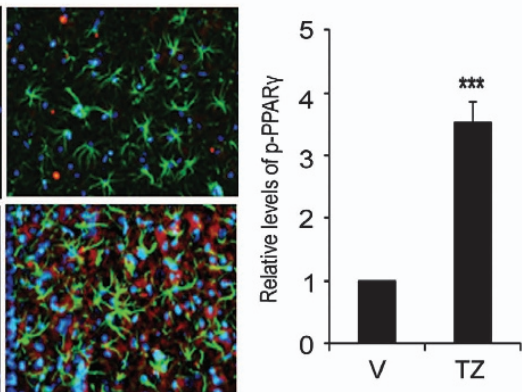

MERGED

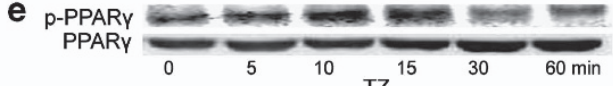

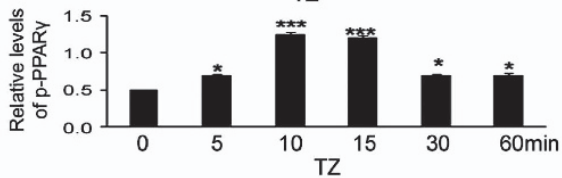

9 p-PPAR

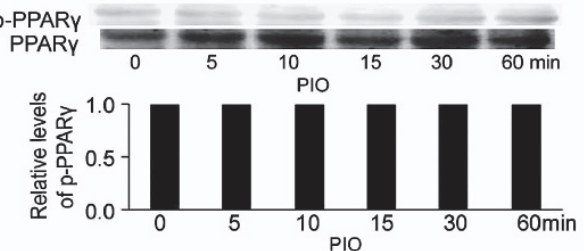

h

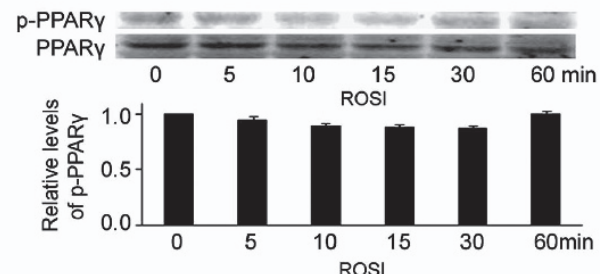

Figure 2 (see next page for Figure caption) 
Effect of TZ on GFAP and p-PPAR $\gamma$ and on astrocyte morphology. To understand the regulatory role of p-PPAR $\gamma(\mathrm{S} 112)$ in astrocytes, we treated developing rats with TZ. TZ suppressed GFAP (Figure 2a), and the area, perimeter and process number of astrocytes (Figure $2 b$ ). The astrocyte count reduced by $0.7662 \pm 0.08582$-fold. (To determine whether reduction in GFAP altered astrocyte morphology, we silenced GFAP gene in cultured astrocytes. We observed a reduction in area, perimeter and process number (Supplementary Figure 1)). To confirm TZ-mediated astrocyte damage, we determined the effect of $\mathrm{TZ}$ on $\mathrm{S} 100 \beta$ and glutamine synthetase-immunolabeled astrocytes. We observed that $\mathrm{TZ}$ reduced immunoreactive intensity of $\mathrm{S} 100 \beta$ and glutamine synthetase, as well as the astrocyte cell count (Supplementary Figure 2).

We determined the effect of TZ on p-PPAR $\gamma(\mathrm{S} 112)$ in rat brain astrocytes (in vivo). TZ caused a rise in p-PPAR $\gamma$ (S112) (Figure 2c). We validated the in vivo observations in cultured rat astrocytes that demonstrated a time-dependent fall in GFAP (Figure 2d) and increase in p-PPAR $\gamma$ (S112) (Figure 2e).

To recognize whether the alteration in p-PPAR $\gamma(\mathrm{S} 112)$ and GFAP levels is TZ specific or valid for all thiazolidinediones, we treated cultured astrocytes with rosiglitazone or pioglitazone. We observed that rosiglitazone raised and pioglitazone had no effect on the levels of GFAP (Figure 2f). However, p-PPAR $\gamma$ (S112) was unaffected by both pioglitazone (Figure $2 \mathrm{~g}$ ) and rosiglitazone (Figure $2 \mathrm{~h}$ ). Therefore, upregulation of GFAP by rosiglitazone is p-PPAR $\gamma(\mathrm{S} 112)$ independent. This confirms the p-PPAR $\gamma$ (S112)-dependent downregulation of GFAP observed for MM or TZ.

Effect of MM and $T Z$ on transcriptional regulation of GFAP. To identify genomic involvement of p-PPAR $\gamma(\mathrm{S} 112)$ in regulating GFAP, we performed an in silico analysis of GFAP gene for the presence of PPREs. We found an inverted repeat (IR10: +913 to +934 ) and a direct repeat (DR1: +507 to +519 ) sequence (marked in red) with $P$-values of 0.000789774 and 0.000383786 , respectively as prospective PPREs (Figure $3 a$ and Table 2). To analyze whether MM and TZ stimulated the binding of $p-P P A R \gamma$ (S112) to putative IR10 and DR1 sites, we performed gel mobility shift assays. We observed that MM and TZ induced a shift in the position of DNA band for both IR10 (Figure 3b) and DR1 (Figure 3c), indicating formation of DNA-protein complex. Incubation of nuclear lysates with antibody specific to p-PPAR $\gamma$ (S112) (Figures 3b and c) caused a supershift (supershift binding), confirming the binding of PPREs to p-PPAR $\gamma$ (S112). The specificity of binding was verified through addition of unlabeled probes in competition experiment. To validate that $\mathrm{p}-\mathrm{PPAR} \gamma(\mathrm{S} 112)$ is indeed recruited to the PPRE sites of the GFAP gene, we carried out chromatin immunoprecipitation (ChIP) assay. MM and TZ stimulated an increase in the quantitative PCR (qPCR) products with IR10 (Figure 3d) and DR1 primers (Figure 3e), corroborating the increase in GFAP-PPRE-p-PPAR $\gamma(\mathrm{S} 112)$ complex. To evaluate whether PPRE-p-PPAR $\gamma(\mathrm{S} 112)$ binding repressed the transcriptional activity of GFAP gene, we designed a construct harboring IR10 and DR1 sequences fused to luciferase reporter, and transfected this construct into cultured rat astrocytes. Both $\mathrm{MM}$ and TZ suppressed luciferase reporter activity (Figure 3f) indicating a PPREmediated transcriptional repression of GFAP.

Effect of MM and TZ on the activation of CDK5 and its binding with PPAR $\gamma$. To know whether CDK5 participated in the phosphorylation (S112) of PPAR $\gamma$, we tested for CDK5 activation in rat brain astrocytes (in vivo). Both $\mathrm{MM}$ (Figure 4a) and TZ (Figure 4b) activated CDK5, which is evident from enhanced phosphorylation.

To confirm participation of CDK5 in inducing p-PPAR $\gamma$ (S112), we determined CDK5-PPAR $\gamma$ immune complex formation (through co-immunoprecipitation) in MM- or TZ-treated astrocytes. We observed an augmented CDK5-PPAR $\gamma$ immune complex indicating a direct involvement of CDK5 in PPAR $\gamma$ phosphorylation (Figure 4c). Inactivation of CDK5 with R-CR8 prevented phosphorylation (S112) of PPAR $\gamma$ as well as decrease in GFAP, for MM (Figures $4 d$ and $f$ ) and TZ (Figures $4 e$ and $g$ ).

These results suggest that MM- and TZ-mediated phosphorylation of PPAR $\gamma$ at $\mathrm{S} 112$ is a direct consequence of CDK5 activation and its physical interaction with PPAR $\gamma$.

Effect of MM and TZ on ERK1/2 and JNK and downstream CDK5. We reported earlier that MM activated

\footnotetext{
Figure 2 TZ downregulates GFAP, impairs astrocyte morphology and enhances p-PPAR (S112) expression in rat brain astrocytes. (a) The cortical tissues from vehicle (V)- and TZ-treated rats were immunoblotted for GFAP and $\beta$-actin. Representative western blot (LHS) and densitometry (RHS) of GFAP normalized with $\beta$-actin. Data represent mean \pm S.E. of five pups from five litters. ${ }^{*} P<0.01$ (compared with V). (b) Five- $\mu$ m-thick cryostat sections of cerebral cortex (coronal section) from V-and TZ-treated rats were stained for GFAP. LHS: Representative photomicrograph ( $\times 100$ magnification) of an GFAP-immunostained astrocyte (green fluorescence), and RHS: relative area, parameter and number of processes in the GFAP-immunostained astrocyte. Sections are representatives of four rats from four different litters, and bar diagrams represent mean \pm S.E. ${ }^{* * *} P<0.001$ and ${ }^{* *} P<0.01$ (compared with V). (c) Five- $\mu$ m-thick cryostat sections of cerebral cortex (coronal section) from V-and TZ-treated rats were co-labeled for p-PPAR $\gamma$ (S112), GFAP and nuclear Hoechst. LHS: Representative photomicrograph ( $\times 20$ magnification) of p-PPAR $\gamma($ S112) (red fluorescence), GFAP (green fluorescence) and nucleus (blue fluorescence), and the three merged in the same field. RHS: The p-PPAR $\gamma /$ GFAP ratio normalized with nuclear Hoechst. Sections are representatives of four rats from four different litters, and bar diagrams represent mean $\pm S$.E. ${ }^{* \star \star} P<0.001$ (compared with V). Rat primary astrocytes were pre-incubated in reduced serum medium for $60 \mathrm{~min}$ and then co-treated with TZ for the indicated time points. (d) Representative western blot (upper panel) and densitometry (lower panel) of GFAP relative to $\beta$-actin in TZ-treated astrocytes. Data represent mean \pm S.E. of four independent experiments in triplicate. ${ }^{* \star *} P<0.001$ and ${ }^{* \star} P<0.01$ (compared with $0 \mathrm{~h}$ ). (e) Representative western blot (upper panel) and densitometry (lower panel) of p-PPAR $\gamma$ (S112) relative to PPAR $\gamma$ in TZ-treated astrocytes. Data represent mean \pm S.E. of four independent experiments in triplicate. ${ }^{* \star} P<0.001$ and ${ }^{\star} P<0.05$ (compared with $0 \mathrm{~min}$ ). Rat primary astrocytes were pre-incubated in reduced serum medium for 60 min and then co-treated with pioglitazone (Pio) or rosiglitazone (Rosi). (f) Representative western blot (upper panel) and densitometry (lower panel) of GFAP relative to $\beta$-actin in Pio- or Rosi-treated astrocytes after $18 \mathrm{~h}$. Data represent mean \pm S.E. of four independent experiments in triplicate. ${ }^{*} P<0.01$ (compared with V). (g) Representative western blot (upper panel) and densitometry (lower panel) of p-PPAR $\gamma(\mathrm{S} 112)$ relative to PPAR $\gamma$ in Pio-treated astrocytes at indicated time points. (h) Representative western blot (upper panel) and densitometry (lower panel) of p-PPAR $\gamma$ (S112) relative to PPAR $\gamma$ in Rosi-treated astrocytes at indicated time points. Data represent mean \pm S.E. of four independent experiments in triplicate
} 


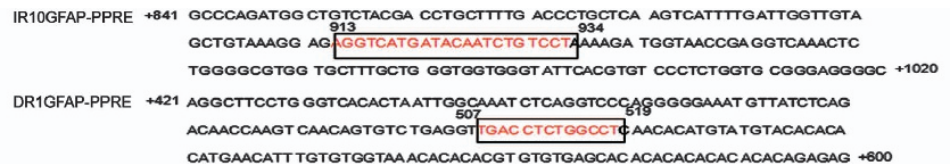

b

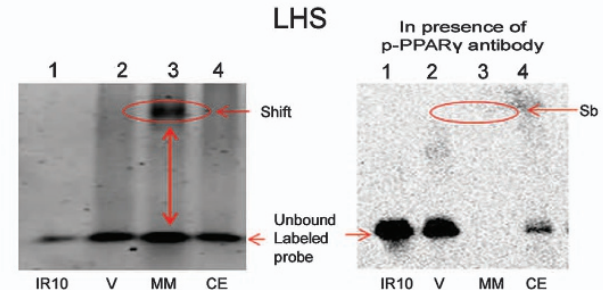

C

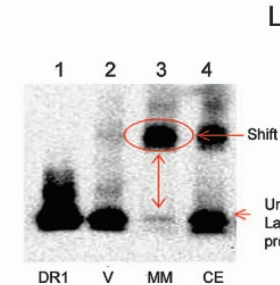

LHS

IR10 V MM CE
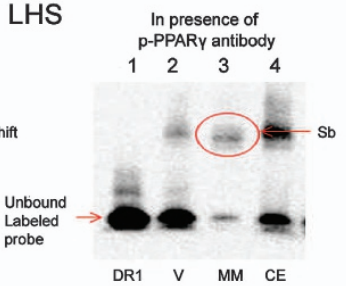
$\begin{array}{lll}\text { p-PPARY antibody } \\ 1 & 2 & 3\end{array}$

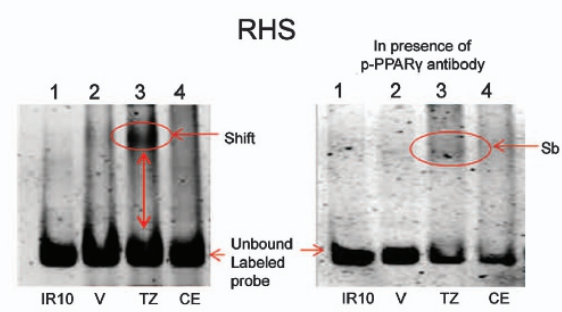

RHS

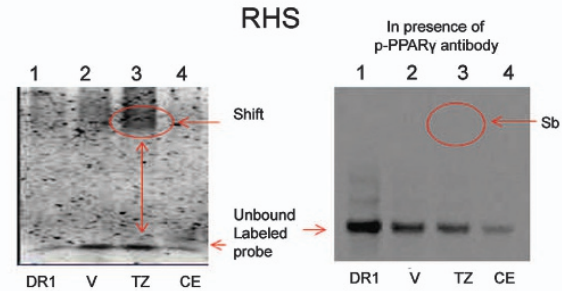

d

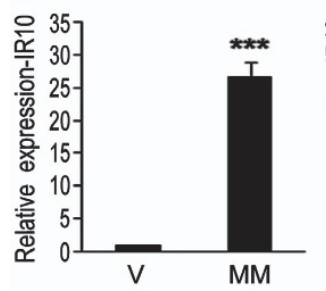

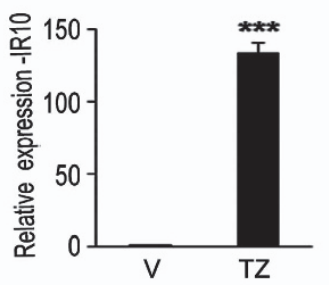
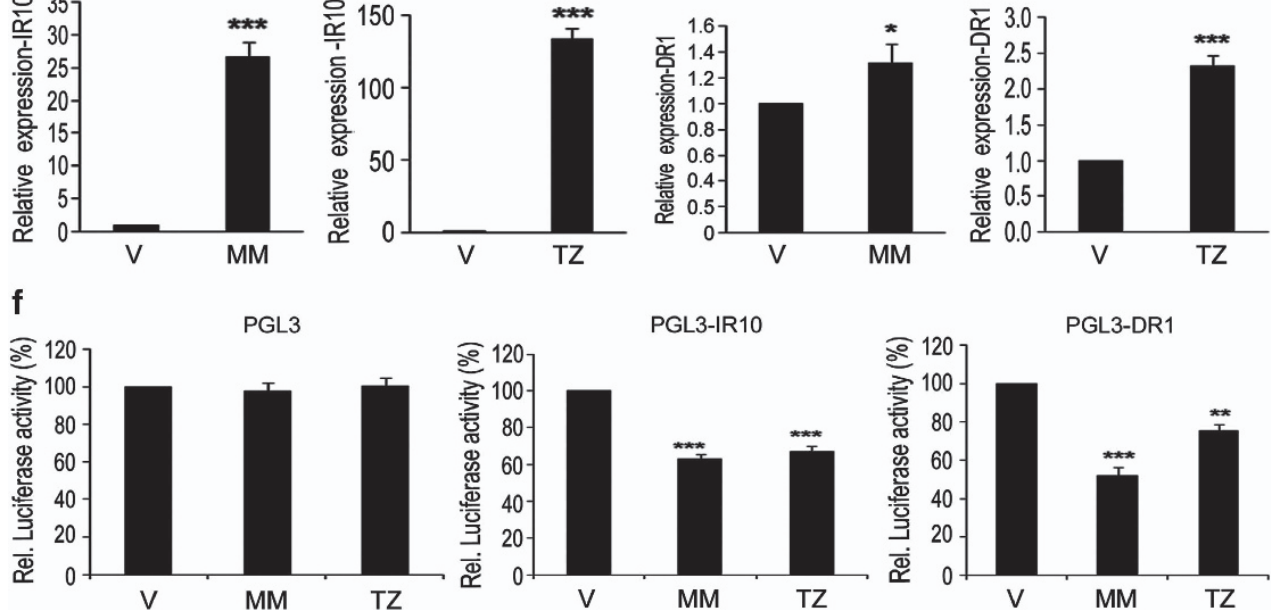

Figure $3 \mathrm{MM}$ and TZ downregulate GFAP by increased p-PPAR $\gamma$ binding to GFAP promoter in rat brain astrocytes. (a) GFAP gene sequence was analyzed through NUBIscan and two PPREs of higher significance (Table 2) were selected. Upper panel: Representative sequence of GFAP gene containing IR10. Lower panel: Representative sequence of GFAP gene containing DR1 sequence. (b) The rat primary astrocytes were treated with MM or TZ for $12 \mathrm{~h}$. The nuclear lysates were collected and incubated with IR10 oligonucleotide probes for 20 min in absence or presence of anti-p-PPAR $\gamma$ (S112) antibody. The DNA-protein complexes were analyzed by EMSA. LHS: Representative blot showing shift of IR10 DNA band relative to unbound DNA, for MM, in absence or in presence of anti-p-PPAR $\gamma$ (S112) antibody. RHS: Representative blot showing shift of IR10 DNA band relative to unbound DNA, for TZ, in absence or in presence of anti-p-PPAR (S112) antibody. Note the supershifted DNA-protein complex (sb: supershifted band). Lane 1: labeled probe only; lane 2: labeled probe + protein from vehicle (V)-treated astrocytes; lane 3: labeled probe + protein from MM- or TZ-treated astrocytes; lane 4: labeled probe + unlabeled probe + protein from MM- or TZ-treated astrocytes (competition experiment, CE). The data shown are representative of three separate experiments. (c) The rat primary astrocytes were treated with MM or TZ for $12 \mathrm{~h}$. The nuclear lysates were collected and incubated with DR1 oligonucleotide probes for 20 min in absence or in presence of anti-p-PPAR $\gamma$ (S112) antibody. The DNA protein complexes were analyzed by EMSA. LHS: Representative blot showing shift of DR1 DNA band relative to unbound DNA, for MM, in absence or in presence of anti-p-PPAR (S112) antibody. RHS: Representative blot showing shift of DR1 DNA band relative to unbound DNA, for TZ, in absence or in presence of anti-p-PPAR ( (S112) antibody. Note the supershifted DNA-protein complex (sb: supershifted band). Lane 1: labeled probe only; lane 2: labeled probe + protein from V-treated astrocytes; lane 3: labeled probe + protein from MM- or TZ-treated astrocytes; lane 4: labeled probe + unlabeled probe + protein from MM- or TZ-treated astrocytes (CE). The data shown are representative of three separate experiments. Rat primary astrocytes were treated with MM or TZ for $12 \mathrm{~h}$. Cells were fixed and ChIP was performed with anti-p-PPAR (S112) antibody. The precipitated DNA was then amplified through real-time PCR using IR10 or DR1 primers. (d) Representative bar diagrams showing fold change of IR10 DNA relative to V in MM- or TZ-exposed astrocytes. Data represent mean \pm S.E. of four independent experiments in triplicate. ${ }^{* \star *} P<0.001$ (compared with V). (e) Representative bar diagrams showing fold change of DR1 DNA relative to V in MM- or TZ-exposed astrocytes. Data represent mean $\pm S$.E. of four independent experiments in triplicate. ${ }^{* *} P<0.001$ and ${ }^{*} P<0.05$ (compared with V). (f) The rat primary astrocytes were transfected with pGL3, pGL3-IR10 or pGL3-DR1 constructs, and then treated with $\mathrm{V}, \mathrm{MM}$ or TZ for $18 \mathrm{~h}$. The luciferase activity was measured and expressed as percentage relative to activity of empty vector. ${ }^{* \star *} P<0.001$ and ${ }^{* \star} P<0.01$ (compared with V) 
MEK1/2 (assessed by ERK1/2) and downstream JNK pathways, and thereby affected cultured astrocytes. ${ }^{26}$ We validated the data in vivo (Figures $5 \mathrm{a}$ and $\mathrm{b}$ ) in which we observed an MM-mediated increase in p-ERK1/2 and p-JNK in astrocytes of rat brain. We determined whether the same phenomenon was valid for TZ. TZ caused an increase in p-ERK1/2 (Figure 5c) and p-JNK (Figure 5d) in rat brain astrocytes (in vivo), which was further validated in vitro

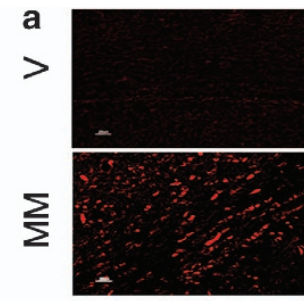
$\mathrm{p}-\mathrm{CDK} 5$
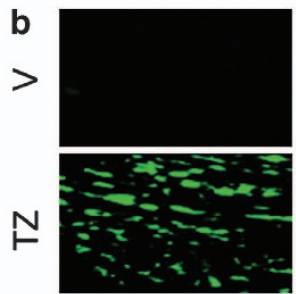

p-CDK5

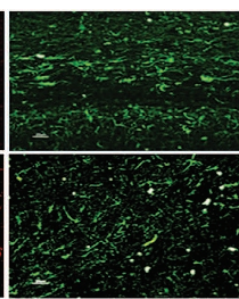

C

$$
\frac{\text { IP }}{V \text { MM TZ }} \frac{\text { INPUT }}{V \text { MM TZ }}
$$

IP: PPARY IB:CDK5

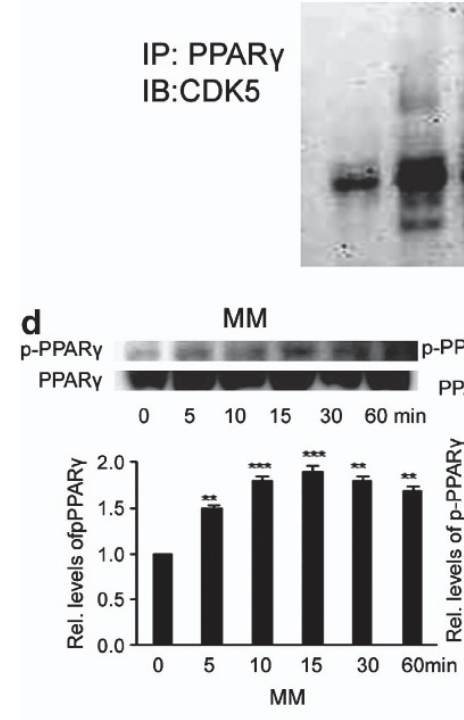

f
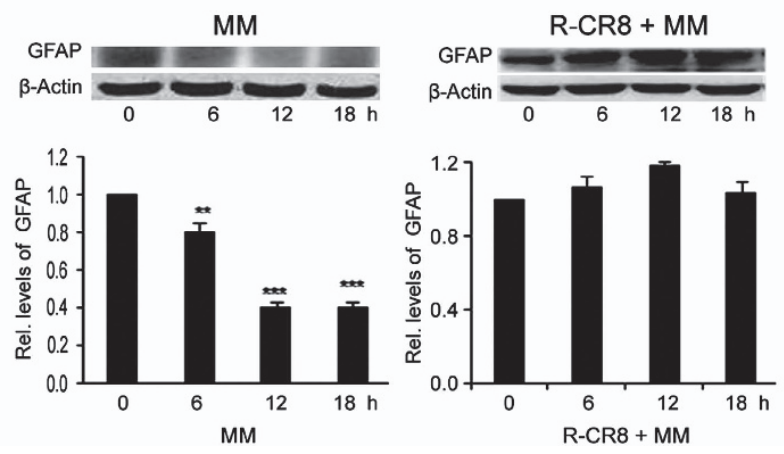

GFAP

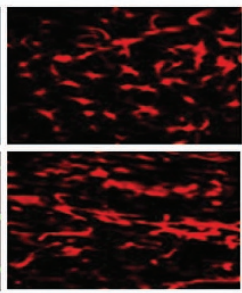

GFAP

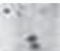

CDK5

$35 \mathrm{kDa}$

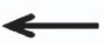

R-CR8 + MM
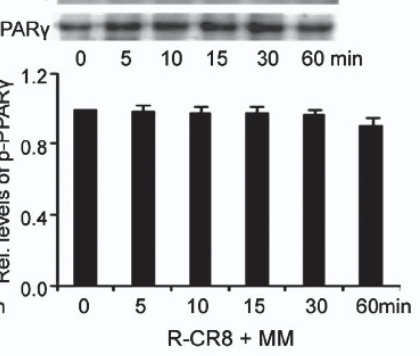

g

IP: PPARY

IB: PPARY

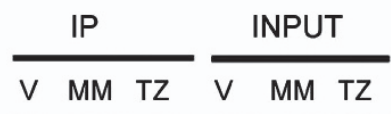

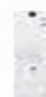

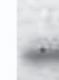

PPARY

$55 \mathrm{kDa}$

MERGED

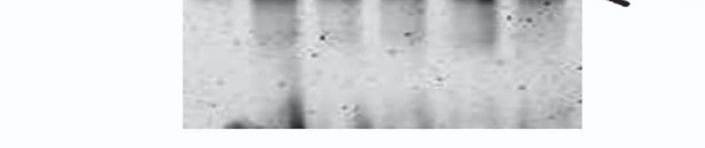

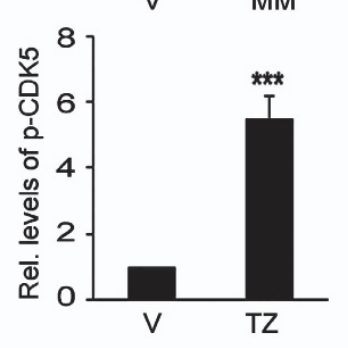
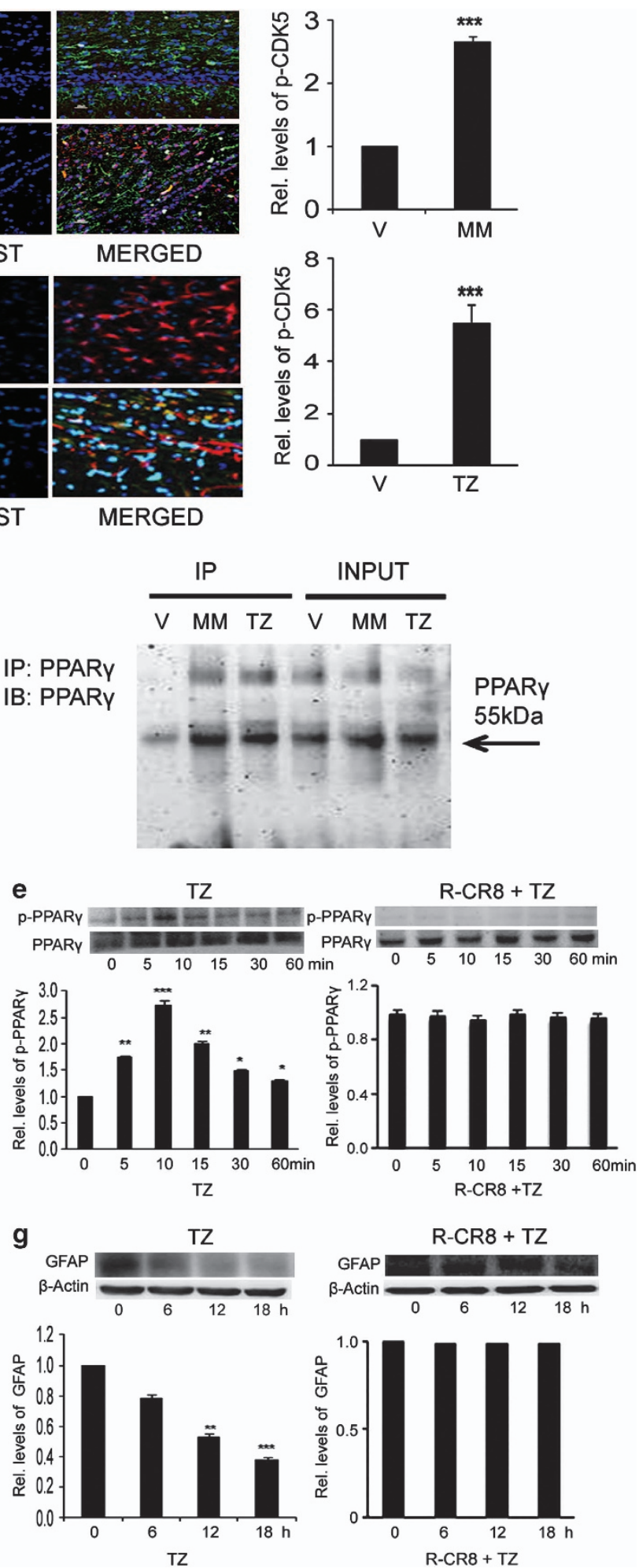
(Figure 5e). Inhibiting MEK1/2 with PD98059 prevented TZ-mediated rise in p-JNK, indicating JNK as downstream to MEK1/2 (Figure 5f).

We investigated whether upregulation of $\mathrm{p}-\mathrm{CDK} 5$ by $\mathrm{MM}$ or TZ was dependent on MEK1/2 and JNK. PD98059 and the JNK inhibitor, SP600125, inhibited phosphorylation of CDK5 for both MM (Figure $5 \mathrm{~g}$ ) and TZ (Figure 5h), indicating ERK1/ 2- and JNK-dependent activation of CDK5. We further observed that PD98059 and SP600125 restricted the rise in p-PPAR $\gamma$ (S112) (Supplementary Figures 3 and 4) and fall in GFAP (Supplementary Figures 5 and 6).

Effect of MM and TZ on astrogliosis. Increased expression of GFAP induces astroglial activation and gliosis during neurodegeneration. ${ }^{30} \mathrm{We}$, therefore, investigated whether TZ or MM could serve as neuroprotective agents by their ability to downregulate GFAP. We induced astrogliosis by treating astrocytes with lipopolysaccharide (LPS), ${ }^{31}$ and cotreated with $T Z$ or MM. We found that $T Z$ reduced GFAP levels (Figure 6), suggesting its GFAP-regulating function in pathological conditions. Co-treatment of MM and LPS killed the astrocytes (data not shown).

Therefore, it could be construed that MM- and TZ-mediated modulation in p-PPAR $\gamma(\mathrm{S} 112)$ and GFAP involved sequential activation of ERK $\rightarrow$ JNK $\rightarrow$ CDK5, followed by physical interaction between CDK5 and PPAR $\gamma$ and consequent phosphorylation of PPAR $\gamma$ at S112 (Figure 7).

\section{Discussion}

The present study for the first time proposes a model (Figure 7) whereby increased p-PPAR $\gamma$ (S112) downregulates GFAP by binding to IR10 and DR1 response elements in GFAP gene. TZ in close resemblance with MM (a) stimulates ERK $\rightarrow$ JNK $\rightarrow$ CDK5-mediated phosphorylation (S112) of PPAR $\gamma$, (b) enhances p-PPAR $\gamma$ (S112) binding to GFAP-PPREs, (c) reduces GFAP, and (d) disrupts astrocyte morphology in developing brain.

PPAR $\gamma$ antagonists are reported to suppress glial scar formation by way of reduced astrocyte differentiation in mouse embryonic stem cells. ${ }^{12}$ On the contrary, PPAR $\gamma$ agonists exhibit protective effect in spinal neuroimmune activation, ${ }^{32}$ amyotrophic lateral sclerosis ${ }^{33,34}$ and retinal ischemia/reperfusion injury $^{35}$ via reduced gliosis and modulated GFAP. However, the studies either fail to offer in vivo confirmation or focus only on the anti-inflammatory feature of PPAR $\gamma$ functioning. They lack investigating the genomic regulation of GFAP by PPAR $\gamma$. Here we verify the GFAP-regulating role of PPAR $\gamma$ both in vitro and in vivo. We further unearth a mechanism of GFAP regulation through DNA binding of PPAR $\gamma$. The MM-treated developing rats showing reduced GFAP in developing brain ${ }^{26}$ served as a tool for the purpose. To confirm the involvement of PPAR $\gamma$ signaling, TZ-treated developing rats provided an excellent support. TZ-mediated astrocyte damage was further confirmed through the downregulated expressions of $\mathrm{S} 100 \beta$ and glutamine synthetase (Supplementary Figure 2) that also qualify as astrocyte markers. However, detailed investigation on this is needed.

We prove that the fall in GFAP is mediated through p-PPAR $\gamma$ (S112). Post-translational modifications represent a vital molecular mechanism to regulate the activity of PPAR $\gamma .{ }^{17,36}$ Phosphorylation at Ser112 is a major posttranslational modification, ${ }^{37}$ and mutation at the site alters transcriptional and adipogenic activity of PPAR $\gamma{ }^{38,39}$ We find that the augmented p-PPAR $\gamma$ (S112) repressed GFAP, resulting in altered astrocyte morphology in developing brain. Suppression of $p-P P A R \gamma$ (S112) prevented the fall in GFAP and further raised its (GFAP) level above vehicle. Therefore, although PPAR $\gamma$ target genes are affected by PPAR $\gamma$ phosphorylation in a tissue-specific manner, ${ }^{40}$ a common conformational transformation from PPAR $\gamma$ to $\mathrm{p}-\mathrm{PPAR} \gamma$ (S112) may account for transpression.

However, downregulation of GFAP is not a uniform characteristic of the thiazolidinediones. Pioglitazone and rosiglitazone unaltered and raised levels of GFAP, respectively. Probably, the inability to induce p-PPAR $\gamma$ (S112) distinguishes pioglitazone and rosiglitazone from TZ in terms of their effects on GFAP in astrocytes.

Despite reports of PPAR $\gamma$ and GFAP sharing several regulatory activities, ${ }^{41,42}$ whether PPAR $\gamma$ binds to GFAP gene is unknown. Using a combination of computer-assisted analysis, gel shift, ChIP and transient transfection assays, we identified the two functional PPREs IR10 and DR1 within the non-coding region of GFAP gene, located at +913 and +507 , respectively, from the transcription initiation site. Both MM and TZ increased the binding of p-PPAR $\gamma$ (S112) to IR1

Figure 4 MM and TZ activate CDK5 and induce binding of CDK5 with PPAR $\gamma$, resulting in increased p-PPAR $(\mathrm{S} 112$ ) and reduced GFAP in rat brain astrocytes. Five- $\mu \mathrm{m}$ thick cryostat sections of cerebral cortex (coronal section) from vehicle (V)- and MM-treated rats were co-labeled for $p$-CDK5, GFAP and nuclear Hoechst. (a) Representative photomicrograph ( $\times 20$ magnification) of p-CDK5 (red fluorescence), GFAP (green fluorescence) and nucleus (blue fluorescence), and the three merged in the same field for MM (LHS). The p-CDK5/GFAP ratio normalized with nuclear Hoechst, for MM (RHS). Sections are representatives of four rats from four different litters, and bar diagrams represent mean $\pm S . E .{ }^{* * *} P<0.001$ (compared with V). (b) Representative photomicrograph ( $\times 20$ magnification) of p-CDK5 (green fluorescence), GFAP (red fluorescence) and nucleus (blue fluorescence), and the three merged in the same field for TZ (LHS). The p-CDK5/GFAP ratio normalized with nuclear Hoechst for TZ (RHS). Sections are representatives of four rats from four different litters, and bar diagrams represent mean $\pm S$.E. ${ }^{* \star *} P<0.001$ (compared with V). (c) Rat primary astrocytes were treated with MM or TZ for $15 \mathrm{~min}$. The cell lysates were collected and subjected to immune precipitation with PPAR $\gamma$ antibody. Immunoprecipitated (IP) complexes along with input samples were resolved on SDS-PAGE and immunoblotted (IB) with CDK5 or PPAR $\gamma$ antibodies. Representative blots of CDK5 (LHS) and PPAR (RHS) IP by PPAR $\gamma$. Results are representative of three independent experiments. Rat primary astrocytes were pre-incubated in reduced serum medium, or R-CR8 in reduced serum medium, and then co-treated with MM or TZ for the indicated time points. (d) Representative western blot (upper panel) and densitometric analysis (lower panel) of p-PPAR (S112) relative to PPAR $\gamma$ for MM or R-CR8 with MM. Data represent mean \pm S.E. of four independent experiments in triplicate. ${ }^{* * *} P<0.001$ and ${ }^{* *} P<0.01$ (compared with 0 min). (e) Representative western blot (upper panel) and densitometric analysis (lower panel) of p-PPAR $\gamma$ (S112) relative to PPAR $\gamma$ for TZ or R-CR8 with TZ. Data represent mean \pm S.E. of four independent experiments in triplicate. ${ }^{* \star *} P<0.001,{ }^{* *} P<0.01$ and ${ }^{\star} P<0.05$ (compared with 0 min). (f) Representative western blot (upper panel) and densitometric analysis (lower panel) of GFAP relative to $\beta$-actin for MM or R-CR8 with MM. Data represent mean \pm S.E. of four independent experiments in triplicate. ${ }^{* * \star} P<0.001$ and ${ }^{* \star} P<0.01$ (compared with 0 h). (g) Representative western blot (upper panel) and densitometric analysis (lower panel) of GFAP relative to $\beta$-actin for TZ or R-CR8 with TZ. Data represent mean \pm S.E. of four independent experiments in triplicate. ${ }^{* \star *} P<0.001$ and ${ }^{* \star} P<0.01$ (compared with $0 \mathrm{~h}$ ) 
and DR10, and suppressed luciferase activity in astrocytes transfected with luciferase reporters driven by these PPREs. Therefore, our data divulges that an enhanced interaction of p-PPAR $\gamma$ (S112) to the GFAP-PPREs represses the gene. Probably, the phosphorylation at $\mathrm{S} 112$ stabilizes an inactive conformation of PPAR $\gamma$ by recruiting negative co-regulators and co-repressors, turning off the activated GFAP gene.

We bring forth, for the first time, a CDK5-mediated phosphorylation of PPAR $\gamma$ in astrocytes. CDK5 has been reported to associate with its strongest and best characterized activator,
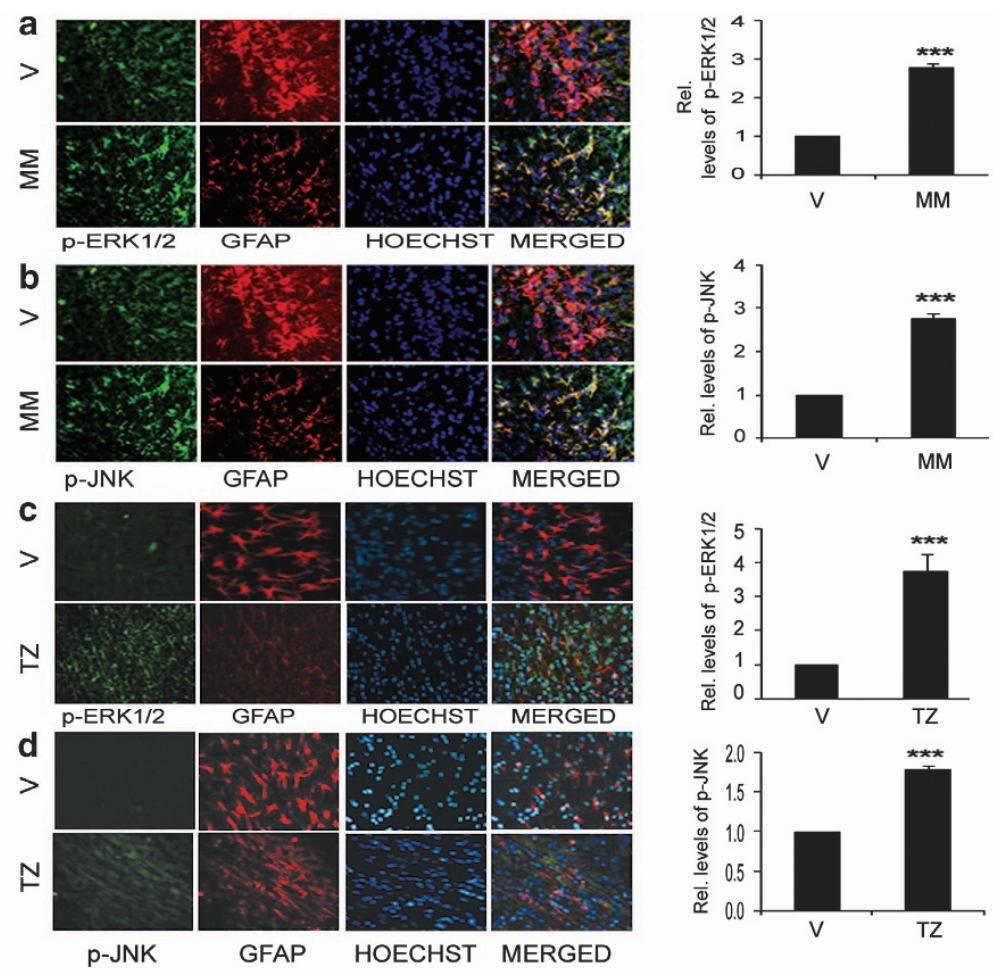

e p-ERK1/2

ERK1/2

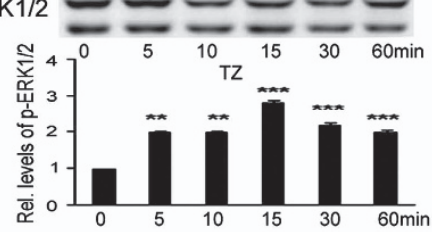

g

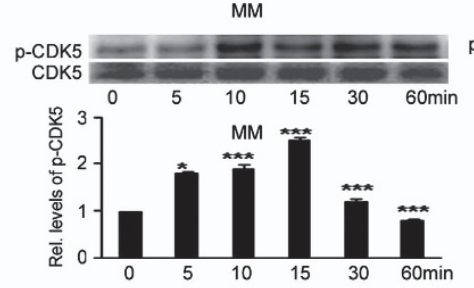

h

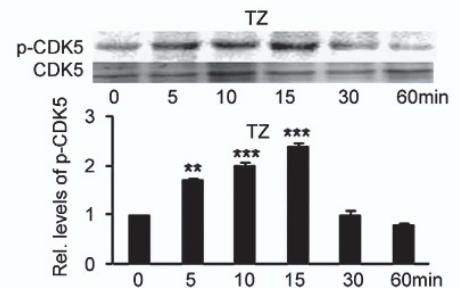

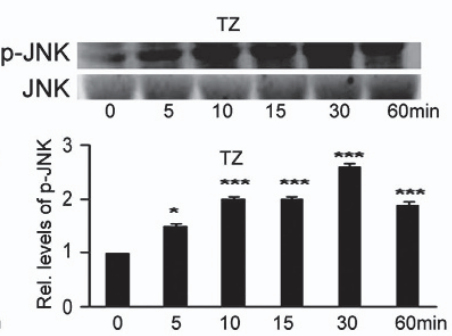

PD98059 + MM
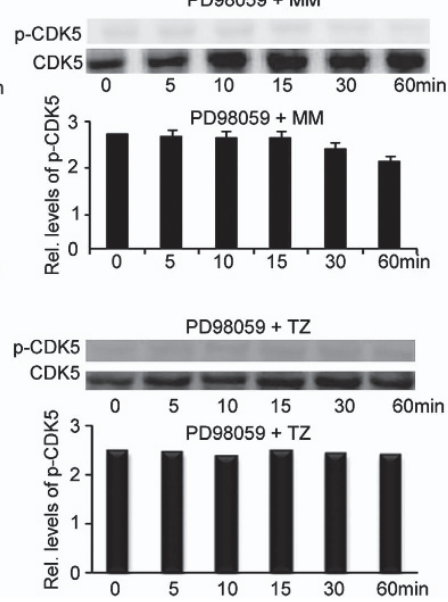
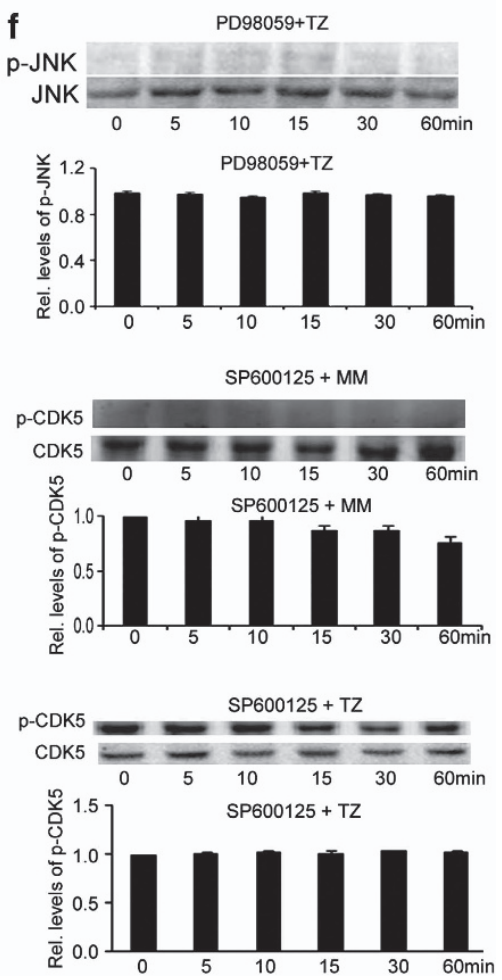
P35, and phosphorylate PPAR $\gamma$ in adipose ${ }^{43}$ and pancreatic $\beta$ cells. ${ }^{44}$ Further, CDK5 forms an immune complex with p35 ${ }^{45}$ that contributes to the altered morphology and process extension in astrocytes, and in the reorganization of GFAP cytoskeleton in pathological situations. ${ }^{46}$ Therefore, it may well be assumed that CDK5-mediated phosphorylation (probably by complexing with P35, which needs to be probed) of PPAR $\gamma$ is a pertinent reason behind the adverse changes in astrocytes.

S112 phosphorylation at the NH2-terminal (A/B domain) by MAPKs ${ }^{15}$ modulates ligand-binding affinity of PPAR $\gamma$ and negatively regulates transcriptional and biological functions of

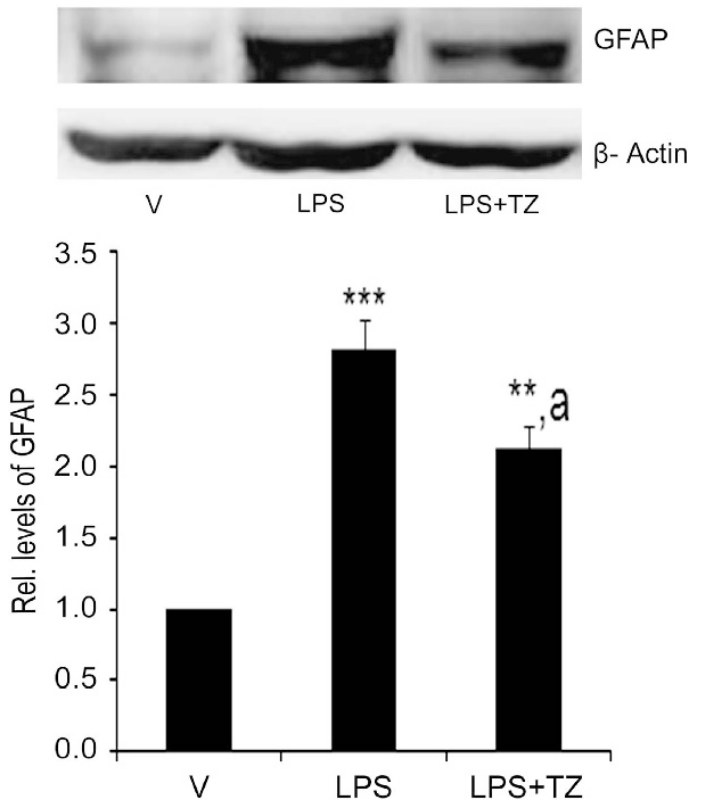

Figure 6 TZ reduces astrogliosis during neurodegeneration. The rat primary astrocytes were pre-treated with LPS and then treated with vehicle (V), LPS or TZ and LPS for $18 \mathrm{~h}$. Representative western blot (upper panel) and densitometric analysis (lower panel) of GFAP relative to $\beta$-actin. Data represent mean \pm S.E. of four independent experiments in triplicate. ${ }^{* \star *} P<0.001$, ${ }^{* *} P<0.01$ (compared with V) and ${ }^{\mathrm{a}} P<0.05$ (compared with LPS alone)
PPAR $\gamma .{ }^{47}$ Activation of MAPKs and JNK by stress results in enhanced phosphorylation of PPAR $\gamma$ at S112. ${ }^{17}$ The MAPKs directly couple to the receptor controlling a variety of target genes involved in lipid homeostasis. ${ }^{38,48}$ Here, in brain astrocytes, we observed a participation of ERK1/2 and JNK in the generation of $p-P P A R \gamma(S 112)$ and repression of GFAP. However, it occurs by intermediate involvement of CDK5 that directly interacts with PPAR $\gamma$. Ours is the first report on CDK5mediated phosphorylation of S112. Serine 273 is also an important site for phosphorylation of PPAR $\gamma .{ }^{19,21,49}$ However, we are yet to determine whether the modulation in GFAP levels by MM and TZ involved any hyper phosphorylation of serine 273.

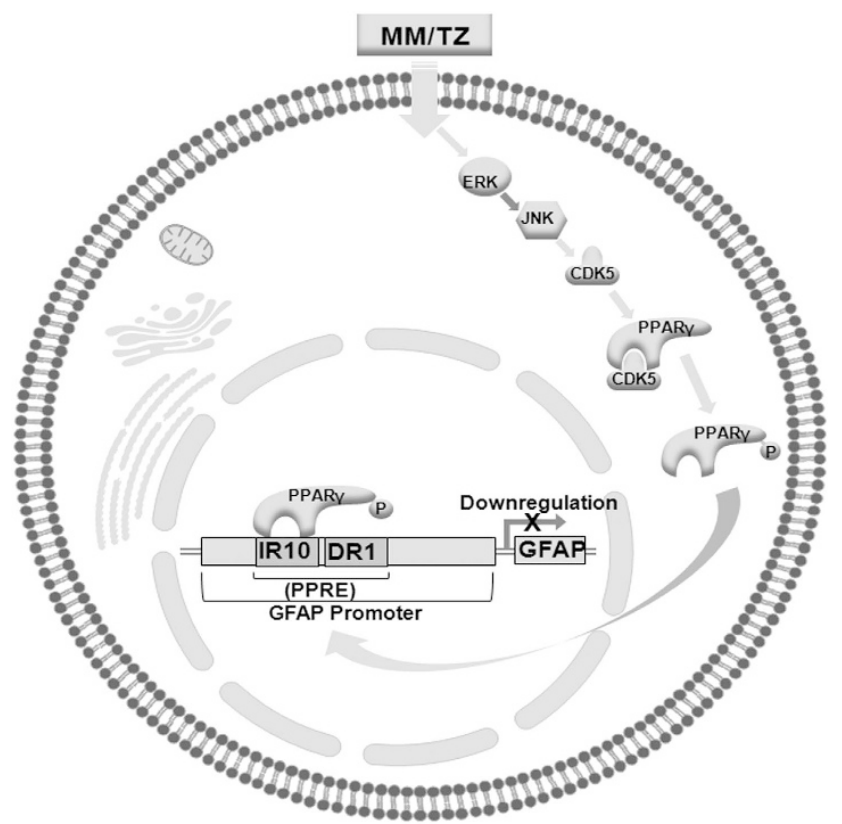

Figure 7 Proposed schematic diagram of MM- and TZ-mediated GFAP downregulation in astrocytes of rat brain. The MM and TZ induces sequential activation of ERK1/2, JNK and CDK5. The CDK5 binds to the PPAR $\gamma$, enhances p-PPAR $\gamma($ S112) that suppresses GFAP

Figure $5 \mathrm{MM}$ and TZ activate MEK1/2 $\rightarrow \mathrm{JNK} \rightarrow \mathrm{CDK} 5$ in rat brain astrocytes. Five- $\mu \mathrm{m}$-thick cryostat sections of cerebral cortex (coronal section) from vehicle $(\mathrm{V})$ - or MM- or TZ-treated rats were stained for $p$-ERK1/2 or p-JNK followed by GFAP and nuclear Hoechst co-stain. (a) Representative photomicrograph ( $\times 20$ magnification) of $\mathrm{p}$-ERK1/2 (green fluorescence), GFAP (red fluorescence) and nucleus (blue fluorescence), and the three merged in the same field for MM (LHS). The p-ERK1/2/GFAP ratio normalized with nuclear Hoechst (RHS). (b) Representative photomicrograph ( $\times 20$ magnification) of p-JNK (green fluorescence), GFAP (red fluorescence) and nucleus (blue fluorescence), and the three merged in the same field (LHS) for MM. The p-JNK/GFAP ratio normalized with nuclear Hoechst (RHS). (c) Representative photomicrograph ( $\times 20$ magnification) of $p$-ERK1/2 (green fluorescence), GFAP (red fluorescence) and nucleus (blue fluorescence), and the three merged in the same field for TZ (LHS). The p-ERK1/2/GFAP ratio normalized with nuclear Hoechst (RHS). (d) Representative photomicrograph $(\times 20$ magnification) of p-JNK (green fluorescence), GFAP (red fluorescence) and nucleus (blue fluorescence), and the three merged in the same field for TZ (LHS). The p-JNK/GFAP ratio normalized with Hoechst (RHS). Sections are representatives of four rats from four different litters and bar diagrams represent means $\pm S E$. ${ }^{* \star \star} P<0.001$ (compared with V). (e) Rat primary astrocytes were pre-incubated in serum-free medium and then treated with TZ for the indicated time points. Left panel: Representative western blot and densitometric analysis of $p$-ERK1/2 relative to ERK1/ 2. Right Panel: Representative western blot and densitometric analysis of $p$-JNK relative to JNK. Data represent mean \pm S.E. of four independent experiments in triplicate. ${ }^{* * *} P<0.001,{ }^{* *} P<0.01$ and ${ }^{*} P<0.05$ (compared with $0 \mathrm{~min}$ ). (f) Rat primary astrocytes were pre-incubated with PD98059 in serum-free medium and then co-treated with TZ for the indicated time points. Representative western blot and densitometric analysis of p-JNK relative to JNK. Data represent mean \pm S.E. of four independent experiments in triplicate. (g) Rat primary astrocytes were pre-incubated in reduced serum medium, PD98059 in reduced serum medium or SP600125 in reduced serum medium for 60 min and then co-treated with MM for the indicated time points. Left panel: Representative western blot and densitometric analysis of $p-C D K 5$ relative to CDK5 for MM. Middle panel: Representative western blot and densitometric analysis of p-CDK5 relative to CDK5 for PD98059 + MM. Right panel: Representative western blot and densitometric analysis of $p-C D K 5$ relative to CDK5 for SP600125 + MM. Data represent mean \pm S.E. of four independent experiments in triplicate. ${ }^{* \star *} P<0.001$ and ${ }^{\star} P<0.05$ (compared with $0 \mathrm{~min}$ ). (h) Rat primary astrocytes were pre-incubated in reduced serum medium, PD98059 in reduced serum medium or SP600125 in reduced serum medium for 60 min and then co-treated with TZ for the indicated time points. Left panel: Representative western blot and densitometric analysis of p-CDK5 relative to CDK5, for TZ. Middle panel: Representative western blot and densitometric analysis of $p-C D K 5$ relative to CDK5, for PD98059 + TZ. Right panel: Representative western blot and densitometric analysis of $p$-CDK5 relative to CDK5 for SP600125 + TZ. Data represent mean \pm SE of four independent experiments in triplicate. ${ }^{* \star *} P<0.001$ and ${ }^{* \star} P<0.01$ (compared with 0 min) 
TZ ameliorates ischemic injury from stroke $e^{50,51}$ and alleviates the effects of neurodegenerative diseases. Ischemia and neurodegeneration are largely associated with astrogliosis, characterized by increased expression of immunoreactive GFAP. ${ }^{2}$ Therefore, the question arises whether the neuroprotection by $T Z$ is due to reduction in GFAP. The data on reduced levels of GFAP in LPS-treated astrocytes suggest that our observed GFAP-suppressing role of the TZ may be utilized for neuroprotection during astrogliosis. However, this aspect calls for further confirmation.

Overall, we differ from a prior report where astrocytes were resistant to $\mathrm{TZ}$ even at 30 times higher concentration. ${ }^{27}$ Rather, the strange similarity of $\mathrm{TZ}$ with neurotoxic MM in developing astrocytes invokes the necessity of assessing in detail its effect on neurodevelopment.

Taken as a whole, our study enlightens both the genomic and non-genomic PPAR $\gamma$ signaling pathways to astrocyte damage during brain development. The data claims TZ as a new molecule provoking astrocyte irregularity and distortion in developing brain. It also delves deep into the toxic mechanism of $\mathrm{MM}$ in developing astrocytes. However, a detailed inspection is needed to discern the PPAR $\gamma$ and p-PPAR $\gamma$ molecular mechanism in astrocytes during normal and pathological conditions.

\footnotetext{
Materials and Methods

Reagents and kits. Sodium arsenite, lead acetate, cadmium chloride, sodium orthovanadate, sodium fluoride, ponceau $S$ stain, bromophenol blue, phenylmethylsulfonyl fluoride, protease inhibitor cocktail, dithiothreitol bovine serum albumin acrylamide, bis-acrylamide, sodium dodecyl sulfate (SDS), p-formaldehyde, sucrose, ethylene glycol, agarose, 3-aminopropyltriethoxysilane, polyvinylidene fluoride membrane, ethanol, dimethylformamide, methanol, isopropanol, chloroform, Tris-HCl, Tween 20, Triton X-100, nonyl phenoxypolyethoxylethanol (NP-40), sepharose beads, Hoechst 33258 stain, poly-L-lysine, Tris- $\mathrm{HCl}, \mathrm{NaCl}$, EDTA, EGTA, Triton X-100, mammalian tissue and cell protein extraction reagent and LPS were procured from Sigma Chemical Co. (St. Louis, MO, USA). PD98059, SP600125, Dulbecco's modified Eagle medium: nutrient mixture F-12 cell culture medium, trypsin-EDTA, G-5 supplement, fetal bovine serum, sample loading buffer for western blotting and protein markers were purchased from Invitrogen (Carlsbad, CA, USA). The nuclear and cytoplasmic extraction reagents, supersignal west femto maximum sensitivity substrate, nylon membrane and electrophoretic mobility shift assay (EMSA) kit were purchased from Pierce Biotechnology (Rockford, IL, USA). PPAR- $\gamma$ agonist TZ, rosiglitazone and pioglitazone, PPAR- $\gamma$ antagonist T0070907 and CDK5 inhibitors (R)-CR8 were purchased from Tocris Biosciences (Bristol, UK). Tissue-freezing medium was purchased from Leica Microsystems (Heidelberger Strasse, Germany). Amaxa transfection reagent was purchased from Lonza (Basel, Switzerland). ChIP kit was purchased from Millipore (Temecula, CA, USA). Vectashield mounting medium and Elite $A B C$ kit were purchased from Vector Laboratories (Burlingame, CA, USA). The SYBR Green qPCR kit was purchased from Qiagen (Valencia, CA, USA). The pGL3-basic promoter plasmid vector and luciferase substrate were obtained from Promega (Madison, WI, USA).
}

Antibodies. Rabbit polyclonal antibody to PPAR- $\gamma$ was purchased from Abcam (Cambridge, MA, USA), rabbit polyclonal antibodies to S112-phosphorylated PPAR $\gamma$, phospho CDK5 and CDK5 were purchased from Santa Cruz Biotechnology (Santa Cruz, CA, USA). Rabbit polyclonal antibodies to ERK1/2, JNK1/2, phosphoERK1/2 and phospho-JNK1/2 and anti-acetyl $\mathrm{H} 4$ antibody were purchased from Cell Signaling Technology (Danvers, MA, USA). Rabbit monoclonal antibody to S100beta $(S 100 \beta)$ and rabbit polyclonal antibody to glutamine synthetase were purchased from Cell Signaling Technology and Sigma Chemical Co., respectively. Mouse monoclonal antibodies to GFAP and TATA box-binding protein were obtained from Millipore. Mouse monoclonal antibodies to $\beta$-actin and peroxidaseconjugated secondary antibodies were obtained from Sigma Chemical Co. The Alexa Fluor secondary antibodies were purchased from Invitrogen.
Animals and treatments. All animal handling procedures were performed following the regulations of Institutional Animal Ethics Committee and with their prior approval for using animals. Pregnant female Wistar rats, obtained from the institute animal house, were fed through gavage with MM or water (vehicle) ${ }^{26}$ from gestation day 5 (G5) and continued in lactating rats until postnatal day 16 (P16). The MM was a mixture of 10 times the most frequently occurring concentrations of $\mathrm{As}, \mathrm{Cd}$ and $\mathrm{Pb}$ in Indian ground water. At this dose of exposure, the GFAP levels and astrocyte morphology were adversely affected. TZ and its vehicle were intraperitoneally injected in pups from P1 to P16 at a low dose (Table 1). ${ }^{50}$ The number of pregnant rats per treatment group was 30. After standardization of litters (culling), equal numbers of male and female pups were taken for each experiment, and pups from different litters were independent subjects. ${ }^{52}$

Immunohistochemistry. Immunofluorescence staining of rat brain section was performed according to the previously described method. ${ }^{26}$ Four $\mathrm{P} 16$ pups from four different litters were anesthetized and perfused by phosphate-buffered saline (PBS) followed by $4 \%$ p-formaldehyde, and the brain was cryoprotected in $25 \%$ sucrose. Five-micron transverse sections were made from the coronal sections of the cerebral cortex using cryomicrotome (Microm HM 520; Labcon, Munich, Germany), which were then mounted on 3-aminopropyltriethoxysilanecoated slides. The sections were air dried, antigen-retrieved with Na-citrate buffer (pH 6.0), washed with PBS, incubated for $30 \mathrm{~min}$ in methanol, washed twice with PBS and blocked with $3 \%$ donkey serum in PBS at room temperature for $1 \mathrm{~h}$. The sections were then probed with 1:100 dilution of p-PPAR- $\gamma, p-P 44, p-J N K$, $\mathrm{p}$-CDK5, $S 100 \beta$ and glutamine synthetase, and $1: 400$ dilution of GFAP, overnight at $4{ }^{\circ} \mathrm{C}$, washed thrice with PBS, probed with Alexa Fluor 546 goat anti-mouse IgG conjugate (1:200 dilutions) or Alexa Fluor 488 goat anti-rabbit IgG conjugate (1:200) secondary antibodies, counterstained with Hoechst $33258(0.2 \mathrm{mM})$, washed in PBS, mounted in Vectashield mounting media and visualized under a fluorescence microscope (Nikon Instech Co. Ltd, Kawasaki, Kanagawa, Japan) using $\times 10, \times 20$ and $\times 40$ objectives. The immunofluorescence images were then imported and quantified in ImageJ 1.42q (http://rsb.info.nih.gov/ ij/; developed by Wayne Rasband, National Institutes of Health, Bethesda, MD, USA). ${ }^{26}$ Count of $\mathrm{S} 100 \beta$ or glutamine synthetase immunoreactive astrocytes were quantified with the Shape descriptors plugin of the software. Mean pixel intensity of $S 100 \beta$ or glutamine synthetase fluorescence immunoreactivity were measured by RGB plugin of the software.

Primary astrocyte culture. Astrocytes were cultured from 1-day-old rat brain as described previously. ${ }^{26}$ The cortices were released from the skull cavity, gently transferred to a 60-mm Petri dish, rinsed with PBS, cleaned, put in serumfree medium, mechanically triturated and digested with trypsin for $10 \mathrm{~min}$ at $37^{\circ} \mathrm{C}$. The tissue was rinsed with a squirt of Dulbecco's modified Eagle medium: nutrient mixture F-12 culture medium, containing $10 \%$ fetal bovine serum, $1 \%$ glutamine and antibiotic-antimycotic, and passed through a $80-\mu \mathrm{m}$ nylon mesh. The cells were plated in $75 \mathrm{~cm}^{2}$ poly-L-lysine-coated culture flasks at a concentration of $15 \times 10^{6}$ cells. Upon attachment to the flasks, cells were supplemented with G5. Purity of culture was determined through GFAP immunostaining.

Astrocyte treatment. The astrocytes were grown to $70-80 \%$ confluence, preincubated in reduced serum ( $0.5 \%$ fetal bovine serum) medium for $60 \mathrm{~min}$ and then treated with MM (As-15 $\mu \mathrm{m}, \mathrm{Pb}-25 \mu \mathrm{m}$ and Cd-3 $\mu \mathrm{m}$ mixture), ${ }^{26} \mathrm{TZ}(1 \mu \mathrm{m})$, rosiglitazone $(1 \mu \mathrm{m})$ or pioglitazone $(1 \mu \mathrm{m})$ in reduced serum medium. The involvement of ERK1/2, JNK, CDK5 and PPAR $\gamma$ was determined by pre-incubating the astrocytes for $60 \mathrm{~min}$ in reduced serum medium with PD98059 $(10 \mu \mathrm{m})$, SP600125 $(10 \mu \mathrm{m}),(\mathrm{R})-\mathrm{CR} 8(0.25 \mu \mathrm{m})$ and T0070907 $(10 \mathrm{~nm})$ that are inhibitors to

Table $1 \mathrm{MM}$ and TZ doses (in vivo)

\begin{tabular}{lll}
\hline & Group & Treatment \\
\hline 1 & Vehicle for MM & Water (vehicle) \\
2 & MM & $\mathrm{Pb}\left(\mathrm{C}_{2} \mathrm{H}_{3} \mathrm{O}_{2}\right)_{2}: 2.220$ p.p.m. \\
& & $+\mathrm{CdCl}_{2}: 0.98 \mathrm{p} . \mathrm{p} . \mathrm{m} .+\mathrm{NaAsO}_{2}:$ \\
& & $3.80 \mathrm{p} . \mathrm{p.m}$. \\
3 & Vehicle for $\mathrm{TZ}$ & $\mathrm{MSO}$ \\
4 & TZ & $2.5 \mathrm{mg} / \mathrm{kg}$ body weight/day \\
\hline
\end{tabular}

Abbreviations: MM, metal mixture; TZ, troglitazone 
MEK1/2, JNK, CDK5 and PPAR $\gamma$, respectively, and then co-treating with MM or TZ. The time course of activation of PPAR $\gamma$, CDK5, MEK $1 / 2$ (assessed by ERK $1 / 2$ phosphorylation) and JNK in MM- or TZ-treated astrocytes was determined by preincubating the cells in reduced serum medium for $60 \mathrm{~min}$, and then treating with MM or TZ in reduced serum. To understand the role of MM and TZ in astrogliosis, the astrocytes were pre-incubated in reduced serum medium and then treated with LPS $(1 \mu \mathrm{g} / \mathrm{ml})$ or LPS and MM or TZ in reduced serum medium.

Protein isolation and western blotting. The cultured astrocytes were washed in ice-cooled PBS and suspended in Cellytic Lysis Reagent with protease inhibitor cocktail and $1 \mathrm{mM}$ dithiothreitol. To determine the phosphorylation of JNK, ERK $1 / 2$, CDK5 and PPAR $\gamma$, cells were treated with lysis buffer supplemented with $1 \mathrm{mM}$ sodium orthovanadate and $25 \mathrm{mM}$ sodium fluoride following an optimized protocol. ${ }^{53}$ For brain tissues, P16 cortical tissues were snap frozen in liquid nitrogen and homogenized in tissue lysis buffer following an optimized protocol. ${ }^{54}$ The samples were centrifuged at 15000 r.p.m. for $30 \mathrm{~min}$ at $4{ }^{\circ} \mathrm{C}$. The clear supernatant was taken and protein concentration was determined using a NanoDrop Spectrophotometer (Thermo Scientific, Wilmington, DE, USA). Protein samples $(50-100 \mu \mathrm{g})$ were subjected to $6-15 \%$ SDS-PAGE followed by transfer on polyvinylidene fluoride membrane. The membranes were blocked with $5 \%$ nonfat milk in TBST (10 mM Tris, pH 8.0, $150 \mathrm{mM} \mathrm{NaCl}, 0.01 \%$ Tween 20) for $60 \mathrm{~min}$ at room temperature and probed with primary antibodies against p-PPAR- $\gamma$, PPAR- $\gamma, p$-ERK1/2, ERK1/2, p-JNK, JNK, p-CDK5, CDK5, GFAP or $\beta$-actin (1:1000 to $1: 10000$ dilution) in TBST at $4{ }^{\circ} \mathrm{C}$ overnight. After washing in TBST, the membranes were incubated with mouse or rabbit horseradish peroxidase-conjugated secondary antibodies (1:2000 to $1: 20000$ dilutions) in TBST. The proteins were visualized using chemiluminescence with the supersignal West Femto maximum sensitivity substrate. Densitometric quantification of plots was done using the VersaDoc Gel Imaging System (Bio-Rad, Hercules, CA, USA).

Identification of PPREs on GFAP gene. The PPREs on rat GFAP gene were identified using NUBIscan, an in silico tool for prediction of nuclear receptorbinding site that relies on the combination of nucleotide distribution weight matrices of single-hexamer half sites. ${ }^{55}$ Nucleotide sequence of rat GFAP gene (Gene ID: 24387, Chromosome: 10; NC_005109.3) was scanned on NUBIscan against matrix of weighted PPAR $\gamma$ half sites from previously mentioned experimental data. ${ }^{56}$ Scanning results were further analyzed and PPREs were selected on the basis of their $P$-values (Table 2).

Isolation of nuclear proteins and EMSA. The astrocytes $\left(5 \times 10^{6}\right)$ were collected and washed in ice-cold PBS, resuspended in $500 \mu$ l hypotonic $(10 \mathrm{mM} \mathrm{NaCl}, 3 \mathrm{mM} \mathrm{MgCl}$ and $20 \mathrm{mM}$ Tris- $\mathrm{HCl} ; \mathrm{pH}$ 7.4) buffer, incubated on ice, detergent ( $10 \%$ NP-40)-treated and vortexed for $20 \mathrm{~s}$ followed by centrifugation for $10 \mathrm{~min}$ at 3000 r.p.m. at $4{ }^{\circ} \mathrm{C}$. The cytosolic fraction-containing supernatant was removed and the pellet was washed twice with PBS. The nuclear pellet was resuspended in $50 \mu \mathrm{l}$ of cell lysis buffer, containing $1 \mathrm{mM}$ sodium orthovanadate (Sigma Chemical Co., for $30 \mathrm{~min}$ on ice with vortexing at $10 \mathrm{~min}$ intervals followed by centrifugation at 14000 r.p.m. for $30 \mathrm{~min}$ at $4^{\circ} \mathrm{C}$. The supernatant (nuclear fraction) transferred to a clean prechilled tube and stored at $-80^{\circ} \mathrm{C}$, according to the previously described method. ${ }^{57}$

EMSA was performed using a Light Shifts Chemiluminescent EMSA kit (Pierce Biotechnology) according to the manufacturer's instructions. The IR10 and DR1 oligonucleotides (Table 3) were synthesized by Eurofins MWG Operon (Huntsville, AL, USA), and biotin 3́-end labeling was performed. Binding reactions $(20 \mu \mathrm{l})$ containing $1 \times$ binding buffer, $50 \mathrm{ng} / \mu \mathrm{l}$ poly (dl.dC), biotin-labeled IR10 or DR1 probe (50 femtomole) and nuclear protein $(5 \mu \mathrm{g})$ were prepared and incubated at room temperature for $20 \mathrm{~min}$. For supershift assays, nuclear extracts were pre-incubated with anti-P-PPAR $\gamma$ (ser112) for $1 \mathrm{~h}$ at $4{ }^{\circ} \mathrm{C}$, followed by the addition of a biotin-labeled IR10 or DR1 probes. Specificity of probes was determined in competition experiments through addition of unlabeled probes at 100 -fold molar excess of labeled probes in reaction mixture.

DNA-protein complexes were separated by electrophoresis in $6 \%$ native polyacrylamide gels at $90 \mathrm{~V}$ and transferred to Biodynes B nylon membranes (Thermo scientific, Rockford, IL, USA). The biotin-labeled molecules in the membrane were detected using a chemiluminescent nucleic acid detection module (Pierce Biotechnology). The membrane was briefly soaked in a blocking solution, incubated in conjugate/blocking solution for $15 \mathrm{~min}$, washed four times in wash buffer and once in substrate equilibration buffer, incubated in substrate working solution for $2 \mathrm{~min}$, followed by chemiluminescence visualization on VersaDoc.
ChIP assay. The astrocytes were cross-linked with $1 \%$ formaldehyde and then lysed. The chromatin was harvested and fragmented using sonication and then immunoprecipitated with anti-p-PPAR $\gamma$ antibody or anti-acetyl $\mathrm{H} 4$ antibody (positive control) or mouse lgG1 (negative control). Purified DNA was amplified using two sets (sets 1 and 2; Table 4) of IR10 or DR1 or glyceraldehyde 3-phosphate dehydrogenase-specific primers and quantified by real-time PCR using SYBR Green PCR master mix and the PRISM 7900 HT Fast Real-Time PCR System (PE Applied Biosystems, Foster City, CA, USA).

PPRE reporter assay. The three repeats of the IR10 and DR1 PPREbinding sequence from GFAP gene (Table 5) were synthesized from Eurofins MWG Operon and each were cloned into pGL3-basic promoter plasmid vectors (Promega) at kpnl-Sacl site. The pGL3-basic promoter plasmid, pGL3-IR10 or pGL3-DR1, was co-transfected with green fluorescent protein plasmid (for determining transfection efficiency) into rat primary astrocytes using the cellspecific Amaxa Nucleofactor reagent (Lonza, Basel, Switzerland) and Amaxa electroporator (Amaxa Biosystems, Gaithersburg, MD, USA), following the manufacturer's instructions. The promoter-induced luciferase activity was measured as described previously. ${ }^{58}$

Co-immunoprecipitation. The co-immunoprecipitation was performed according to a previously described method. ${ }^{59}$ Protein lysate from the cultured astrocytes was prepared in non-denaturing lysis buffer $(20 \mathrm{mM}$ Tris- $\mathrm{HCl}, \mathrm{pH}$, $137 \mathrm{mM} \mathrm{NaCl}, 1 \% \mathrm{NP}-40$ and $2 \mathrm{mM}$ EDTA). Per sample, $200 \mu \mathrm{g}$ protein was taken in $500 \mu \mathrm{l}$ buffer and $100 \mu \mathrm{l}$ of sepharose A bead was added for pre-clearing for $30 \mathrm{~min}$ at $4{ }^{\circ} \mathrm{C}$ with gentle mixing. The samples were centrifuged at 14000 r.p.m. at $4^{\circ} \mathrm{C}$ for $10 \mathrm{~min}$. The supernatant was incubated with anti-PPAR $(1: 100$ dilution) or mouse IgG1 antibody for $12 \mathrm{~h}$ at $4{ }^{\circ} \mathrm{C}$ with gentle rotation. Then, $100 \mu$ of sepharose A bead was added and incubated for $4 \mathrm{~h}$ at $4^{\circ} \mathrm{C}$. Beads were precipitated by centrifugation at 14000 r.p.m. at $4{ }^{\circ} \mathrm{C}$ and washed three times with wash buffer (10 mM Tris, pH 7.4, $1 \mathrm{mM}$ EDTA, $1 \mathrm{mM}$ EGTA, pH 8.0, $150 \mathrm{mM} \mathrm{NaCl}, 1 \%$ Triton $\mathrm{X}-100,0.2 \mathrm{mM}$ sodium orthovanadate and protease inhibitor cocktail) followed by protein elution in SDS containing buffer. The eluted proteins were subjected to western blotting for CDK5 or PPAR $\gamma$ proteins. Western blot data from input samples were used as indicator of sample integrity and position of proteins on blot.

siRNA oligonucleotide transfection for GFAP. The primary astrocytes were transfected using Amaxa astrocyte Nucleofactor kit, according to the manufacturer's instructions (Amaxa Biosystems) Supplementary Data. Briefly, the cells were plated and grown to $70-80 \%$ confluence and then trypsinized. Around $1.5 \times 10^{6}$ cells were centrifuged and resuspended in Nucleofactor solution $(0.5 \mathrm{ml}$ supplement mixed with $2.25 \mathrm{ml}$ of Nucleofactor solution provided with the Amaxa kit. Chemically synthesized and annealed oligonucleotide constructs for GFAP (25nM)

Table 2 PPRE sequence of GFAP gene

\begin{tabular}{|c|c|c|c|}
\hline & PPRE & Sequence $\left(5^{\prime}-3^{\prime}\right)$ & $P$-value \\
\hline & $\begin{array}{l}\text { DR1 } \\
\text { IR10 }\end{array}$ & $\begin{array}{l}\text { 5'-AGGCCAgAGGTCA-3' } \\
5^{\prime} \text {-AGGTCAtgatacaatcTGTCCT-3' }\end{array}$ & $\begin{array}{l}0.000383786 \\
0.000789774\end{array}$ \\
\hline
\end{tabular}

Abbreviations: DR1, direct repeat 1; GFAP, glial fibrillary acidic protein; IR10, inverted repeat 10; PPRE, peroxisome proliferator responsive element

Table 3 Oligonucleotide sequence for EMSA

\begin{tabular}{lll}
\hline & PPRE & Sequence $\left(\mathbf{5}^{\prime}-\mathbf{3}^{\prime}\right)$ \\
\hline 1 & DR1 & 5'-CAGGCCAGAGGTCAACCTG \\
& TTGAGGCCAGAGGTCAACCTGT \\
& TGAGGCCAGAGGTCAGAGCT-3' \\
& IR10 & 5'-TACTCTAGGACAGATTGTATCAT \\
& & GACCTGTTACCATCTAGGACAGAT \\
& & TGTATCATGACCTGTTACCATCTAG \\
& GACAGATTGTATCATGACCTC-3'
\end{tabular}

Abbreviations: DR1, direct repeat 1; EMSA, electrophoretic mobility shift assay; IR10, inverted repeat 10 
Table 4 Primer sequences for qPCR in ChIP assay

\begin{tabular}{lll}
\hline 1 & IR10 (Set 1) & F 5'-AGGTCATGATACAATCTGTCCT-3' \\
& & R 5'-GAGGGACACGTGAATACCCA-3' \\
2 & IR10 (Set 2) & F 5'-CCAGATGGCTGTCTACGACC-3' \\
& & R 5'-AGGACAGATTGTATCATGACCTC-3' \\
3 & DR1 (Set 1) & F 5'-GTTGAGGCCAGAGGTCAACCT-3' \\
& & R 5'-ATTGGCAAATCCCAGGTCCC-3' \\
4 & DR1 (Set 2) & F 5'-GAGGCAGTTTACCCAACCCA-3' \\
& & R 5'-AGGTTGACCTCTGGCCTCAAC-3' \\
5 & GAPDH & F 5'-CAGCAAGGATACTGAGAGCAAGAG-3' \\
& & R 5'-GGATGGAATTGTGAGGGAGATG-3' \\
& &
\end{tabular}

Abbreviations: ChIP, chromatin immunoprecipitation; DR1, direct repeat 1; GAPDH, glyceraldehyde 3-phosphate dehydrogenase; IR10, inverted repeat 10; qPCR, quantitative PCR

Table 5 PPRE sequence for cloning

\begin{tabular}{|c|c|c|}
\hline & PPRE & Sequence $\left(5^{\prime}-3^{\prime}\right)$ \\
\hline 1 & DR1 & $\begin{array}{l}\text { 5'-CAGGCCAGAGGTCAACCTGTTGAGGCCAGAGGT } \\
\text { CAACCTGTTGAGGCCAGAGGTCAGAGCT-3' }\end{array}$ \\
\hline 2 & IR10 & $\begin{array}{l}5^{\prime} \text {-TACTCTAGGACAGATTGTATCATGACCTGTTACC } \\
\text { ATCTAGGACAGATTGTATCATGACCTGTTACCATCT } \\
\text { AGGACAGATTGTATCATGACCTC-3' }\end{array}$ \\
\hline
\end{tabular}

Abbreviations: DR1, direct repeat 1; IR10, inverted repeat 10; PPRE, peroxisome proliferator responsive element

were electroporated separately using T-20 program of an Amaxa electroporator. Nontargeting control siRNA ( $25 \mathrm{nM})$ and Pmax-green fluorescent protein plasmid $(2 \mu \mathrm{g}$, to determine the efficiency of transfection) were transfected in the cells as negative control and positive controls, respectively. The cells were then cultured in complete growth medium. ${ }^{60}$

Statistical analysis. Data are presented as mean \pm S.E. of the indicated number of experiments. Data were analyzed by one-way ANOVA followed by Student-Newman-Keuls post hoc test, or one sample $t$-test when appropriate, in SPSS-9.0-software (SPSS Inc., Chicago, IL, USA).

\section{Conflict of Interest}

The authors declare no conflict of interest.

Acknowledgements. Funding from CSIR Network project-INDEPTH and miND is acknowledged. We acknowledge Ms Priyanka Agarwal for helping in immunofluorescence experiments; Ms Nidhi Singh, CSIR-CDRI for helping in reporter assay; Dr. Debabrata Ghosh, CSIR-IITR for helping in making; Figure 7 and Dr Naibedya Chattopadhyay, CSIR-CDRI for useful suggestions in writing the manuscript (CSIR-IITR manuscript no. 3156).

1. Middeldorp J, Hol EM. GFAP in health and disease. Prog Neurobiol 2011; 93: 421-443.

2. Pekny M, Wilhelmsson U, Bogestal YR, Pekna M. The role of astrocytes and complement system in neural plasticity. Int Rev Neurobiol 2007; 82: 95-111.

3. Aldskogius $\mathrm{H}$, Kozlova EN. Central neuron-glial and glial-glial interactions following axon injury. Prog Neurobiol 1998; 55: 1-26.

4. Johnston-Wilson NL, Sims CD, Hofmann JP, Anderson L, Shore AD, Torrey EF et al. Disease-specific alterations in frontal cortex brain proteins in schizophrenia, bipolar disorder, and major depressive disorder. The Stanley Neuropathology Consortium. Mol Psychiatry 2000; 5: 142-149.

5. Alexander WS. Progressive fibrinoid degeneration of fibrillary astrocytes associated with mental retardation in a hydrocephalic infant. Brain 1949; 72: 373-381; 3 pl.

6. Li R, Messing A, Goldman JE, Brenner M. GFAP mutations in Alexander disease. Int J Dev Neurosci 2002; 20: 259-268.

7. Douglas-Escobar M, Weiss MD. Biomarkers of brain injury in the premature infant. Front Neurol 2012; 3: 185.

8. Douglas-Escobar M, Weiss MD. Biomarkers of hypoxic-ischemic encephalopathy in newborns. Front Neurol 2012; 3: 144.
9. Cristiano L, Bernardo A, Ceru MP. Peroxisome proliferator-activated receptors (PPARs) and peroxisomes in rat cortical and cerebellar astrocytes. J Neurocytol 2001; 30: 671-683.

10. Perez-Ortiz JM, Tranque P, Vaquero CF, Domingo B, Molina F, Calvo S et al. Glitazones differentially regulate primary astrocyte and glioma cell survival. Involvement of reactive oxygen species and peroxisome proliferator-activated receptor-gamma. J Biol Chem 2004; 279: 8976-8985.

11. Chattopadhyay N, Singh DP, Heese O, Godbole MM, Sinohara T, Black PM et al. Expression of peroxisome proliferator-activated receptors (PPARS) in human astrocytic cells: PPARgamma agonists as inducers of apoptosis. J Neurosci Res 2000; 61: 67-74.

12. Ghoochani A, Shabani K, Peymani M, Ghaedi K, Karamali F, Karbalaei K et al. The influence of peroxisome proliferator-activated receptor gamma(1) during differentiation of mouse embryonic stem cells to neural cells. Differentiation 2012; 83: 60-67.

13. Tan NS, Michalik L, Desvergne B, Wahli W. Multiple expression control mechanisms of peroxisome proliferator-activated receptors and their target genes. J Steroid Biochem Mol Biol 2005; 93: 99-105.

14. Jiang JG, Johnson C, Zarnegar R. Peroxisome proliferator-activated receptor gammamediated transcriptional up-regulation of the hepatocyte growth factor gene promoter via a novel composite cis-acting element. J Biol Chem 2001; 276: 25049-25056.

15. Burns KA, Vanden Heuvel JP. Modulation of PPAR activity via phosphorylation. Biochim Biophys Acta 2007; 1771: 952-960.

16. Diradourian C, Girard J, Pegorier JP. Phosphorylation of PPARs: from molecular characterization to physiological relevance. Biochimie 2005; 87: 33-38.

17. van Beekum O, Fleskens V, Kalkhoven E. Posttranslational modifications of PPAR-gamma: fine-tuning the metabolic master regulator. Obesity 2009; 17: 213-219.

18. Kono T, Ahn G, Moss DR, Gann L, Zarain-Herzberg A, Nishiki Y et al. PPAR-gamma activation restores pancreatic islet SERCA2 levels and prevents beta-cell dysfunction under conditions of hyperglycemic and cytokine stress. Mol Endocrinol 2012; 26: 257-271.

19. Liu J, Ormo M, Nystrom AC, Claesson J, Giordanetto F. Transient expression, purification and characterisation of human full-length PPARgamma2 in HEK293 cells. Protein Expr Purif 2013; 89: 189-195.

20. Kim E, Chen F, Wang CC, Harrison LE. CDK5 is a novel regulatory protein in PPARgamma ligand-induced antiproliferation. Int J Oncol 2006; 28: 191-194.

21. Li P, Fan W, Xu J, Lu M, Yamamoto H, Auwerx J et al. Adipocyte NCoR knockout decreases PPARgamma phosphorylation and enhances PPARgamma activity and insulin sensitivity. Cell 2011; 147: 815-826.

22. Veeranna, Shetty KT, Takahashi M, Grant P, Pant HC. Cdk5 and MAPK are associated with complexes of cytoskeletal proteins in rat brain. Brain Res Mol Brain Res 2000; 76: 229-236.

23. Ramos-Miguel A, Garcia-Sevilla JA. Crosstalk between cdk5 and MEK-ERK signalling upon opioid receptor stimulation leads to upregulation of activator p25 and MEK1 inhibition in rat brain. Neuroscience 2012; 215: 17-30.

24. Crespo-Biel N, Canudas AM, Camins A, Pallas M. Kainate induces AKT, ERK and cdk5/ GSK3beta pathway deregulation, phosphorylates tau protein in mouse hippocampus. Neurochem Int 2007; 50: 435-442.

25. An JH, Lee SY, Jeon JY, Cho KG, Kim SU, Lee MA. Identification of gliotropic factors that induce human stem cell migration to malignant tumor. J Proteome Res 2009; 8: 2873-2881.

26. Rai A, Maurya SK, Khare P, Srivastava A, Bandyopadhyay S. Characterization of developmental neurotoxicity of $\mathrm{As}, \mathrm{Cd}$, and $\mathrm{Pb}$ mixture: synergistic action of metal mixture in glial and neuronal functions. Toxicol Sci 2010; 118: 586-601.

27. Spagnolo A, Grant EN, Glick R, Lichtor T, Feinstein DL. Differential effects of PPARgamma agonists on the metabolic properties of gliomas and astrocytes. Neurosci Lett 2007; 417: 72-77.

28. Dello Russo C, Gavrilyuk V, Weinberg G, Almeida A, Bolanos JP, Palmer J et al. Peroxisome proliferator-activated receptor gamma thiazolidinedione agonists increase glucose metabolism in astrocytes. J Biol Chem 2003; 278: 5828-5836.

29. Haskew-Layton RE, Payappilly JB, Xu H, Bennett SA, Ratan RR. 15-Deoxy-Delta12, 14-prostaglandin J2 (15d-PGJ2) protects neurons from oxidative death via an Nrf2 astrocyte-specific mechanism independent of PPARgamma. J Neurochem 2013; 124: 536-547.

30. Messing A, Goldman JE, Johnson AB, Brenner M. Alexander disease: new insights from genetics. J Neuropathol Exp Neurol 2001; 60: 563-573.

31. Hao LY, Hao XQ, Li SH, Li XH. Prenatal exposure to lipopolysaccharide results in cognitive deficits in age-increasing offspring rats. Neuroscience 2010; 166: 763-770.

32. Jia HB, Wang XM, Qiu LL, Liu XY, Shen JC, Ji Q et al. Spinal neuroimmune activation inhibited by repeated administration of pioglitazone in rats after $L 5$ spinal nerve transection. Neurosci Lett 2013; 543: 130-135.

33. Kiaei M, Kipiani K, Chen J, Calingasan NY, Beal MF. Peroxisome proliferator-activated receptor-gamma agonist extends survival in transgenic mouse model of amyotrophic lateral sclerosis. Exp Neurol 2005; 191: 331-336.

34. Shibata N, Kawaguchi-Niida M, Yamamoto T, Toi S, Hirano A, Kobayashi M. Effects of the PPARgamma activator pioglitazone on p38 MAP kinase and lkappaBalpha in the spinal cord of a transgenic mouse model of amyotrophic lateral sclerosis. Neuropathology 2008; 28: 387-398.

35. Zhang $X Y$, Xiao $Y Q$, Zhang $Y$, Ye W. Protective effect of pioglitazone on retinal ischemia/ reperfusion injury in rats. Invest Ophthalmol Vis Sci 2013; 54: 3912-3921. 
36. Floyd ZE, Stephens JM. Controlling a master switch of adipocyte development and insulin sensitivity: covalent modifications of PPARgamma. Biochim Biophys Acta 2012; 1822 1090-1095.

37. Tasdelen I, van Beekum O, Gorbenko O, Fleskens V, van den Broek NJ, Koppen A et al. The serine/threonine phosphatase PPM1B (PP2Cbeta) selectively modulates PPARgamma activity. Biochem J 2013; 451: 45-53.

38. Hu E, Kim JB, Sarraf P, Spiegelman BM. Inhibition of adipogenesis through MAP kinase-mediated phosphorylation of PPARgamma. Science 1996; 274: 2100-2103.

39. Yu YH, Liu BH, Mersmann HJ, Ding ST. Porcine peroxisome proliferator-activated receptor gamma induces transdifferentiation of myocytes into adipocytes. J Anim Sci 2006; 84 2655-2665.

40. Compe E, Drane P, Laurent C, Diderich K, Braun C, Hoeijmakers JH et al. Dysregulation of the peroxisome proliferator-activated receptor target genes by XPD mutations. Mol Cell Biol 2005; 25: 6065-6076.

41. Morosetti R, Servidei T, Mirabella M, Rutella S, Mangiola A, Maira G et al. The PPARgamma ligands PGJ2 and rosiglitazone show a differential ability to inhibit proliferation and to induce apoptosis and differentiation of human glioblastoma cell lines. Int J Oncol 2004; 25: 493-502.

42. Lee EY, Lee JE, Park JH, Shin IC, Koh HC. Rosiglitazone, a PPAR-gamma agonist, protects against striatal dopaminergic neurodegeneration induced by 6-OHDA lesions in the substantia nigra of rats. Toxicol Lett 2012; 213: 332-344.

43. Choi JH, Banks AS, Estall JL, Kajimura S, Bostrom P, Laznik D et al. Anti-diabetic drugs inhibit obesity-linked phosphorylation of PPARgamma by Cdk5. Nature 2010; 466 451-456.

44. Ahmed D, Sharma M. Cyclin-dependent kinase 5/p35/p39: a novel and imminent therapeutic target for diabetes mellitus. Int J Endocrinol 2011; 2011: 530274.

45. Honjyo Y, Kawamoto Y, Nakamura S, Nakano S, Akiguchi I. Immunohistochemical localization of CDK5 activator p39 in the rat brain. Neuroreport 1999; 10 : 3375-3379.

46. He Y, Li HL, Xie WY, Yang CZ, Yu AC, Wang Y. The presence of active Cdk5 associated with p35 in astrocytes and its important role in process elongation of scratched astrocyte. Glia 2007; 55: 573-583.

47. Shao D, Rangwala SM, Bailey ST, Krakow SL, Reginato MJ, Lazar MA. Interdomain communication regulating ligand binding by PPAR-gamma. Nature 1998; 396: 377-380.

48. Adams M, Reginato MJ, Shao D, Lazar MA, Chatterjee VK. Transcriptional activation by peroxisome proliferator-activated receptor gamma is inhibited by phosphorylation at a consensus mitogen-activated protein kinase site. J Biol Chem 1997; 272: $5128-5132$.

49. Amato AA, Rajagopalan S, Lin JZ, Carvalho BM, Figueira AC, Lu J et al. GQ-16, a novel peroxisome proliferator-activated receptor gamma (PPARgamma) ligand, promotes insulin sensitization without weight gain. J Biol Chem 2012; 287: 28169-28179.
50. Sundararajan S, Gamboa JL, Victor NA, Wanderi EW, Lust WD, Landreth GE. Peroxisome proliferator-activated receptor-gamma ligands reduce inflammation and infarction size in transient focal ischemia. Neuroscience 2005; 130: 685-696.

51. Victor NA, Wanderi EW, Gamboa J, Zhao X, Aronowski J, Deininger $\mathrm{K}$ et al. Altered PPARgamma expression and activation after transient focal ischemia in rats. Eur J Neurosci 2006; 24: 1653-1663.

52. Holson RR, Freshwater L, Maurissen JP, Moser VC, Phang W. Statistical issues and techniques appropriate for developmental neurotoxicity testing: a report from the ILSI Research Foundation/Risk Science Institute expert working group on neurodevelopmental endpoints. Neurotoxicol Teratol 2008; 30: 326-348.

53. Abbas S, Khan K, Khan MP, Nagar GK, Tewari D, Maurya SK et al. Developmental exposure to $\mathrm{As}, \mathrm{Cd}$, and $\mathrm{Pb}$ mixture diminishes skeletal growth and causes osteopenia at maturity via osteoblast and chondrocyte malfunctioning in female rats. Toxicol Sci 2013; 134: 207-220.

54. Rai NK, Ashok A, Rai A, Tripathi S, Nagar GK, Mitra K et al. Exposure to As, Cd and $\mathrm{Pb}$-mixture impairs myelin and axon development in rat brain, optic nerve and retina. Toxicol Appl Pharmacol 2013; 273: 242-258.

55. Podvinec M, Kaufmann MR, Handschin C, Meyer UA. NUBIScan, an in silico approach for prediction of nuclear receptor response elements. Mol Endocrinol 2002; 16: 1269-1279.

56. Juge-Aubry C, Pernin A, Favez T, Burger AG, Wahli W, Meier CA et al. DNA binding properties of peroxisome proliferator-activated receptor subtypes on various natural peroxisome proliferator response elements. Importance of the 5'-flanking region. J Biol Chem 1997; 272: 25252-25259.

57. Lahiri DK, Ge Y. Electrophoretic mobility shift assay for the detection of specific DNA-protein complex in nuclear extracts from the cultured cells and frozen autopsy human brain tissue. Brain Res Brain Res Protoc 2000; 5: 257-265.

58. Ma QL, Yang F, Rosario ER, Ubeda OJ, Beech W, Gant DJ et al. Beta-amyloid oligomers induce phosphorylation of tau and inactivation of insulin receptor substrate via c-Jun $\mathrm{N}$-terminal kinase signaling: suppression by omega-3 fatty acids and curcumin. $J$ Neurosci 2009; 29: 9078-9089.

59. Bonifacino JS, Dell'Angelica EC. Immunoprecipitation. Curr Protoc Cell Biol 2001; Chapter 7: unit 7.2.

60. Rai A, Maurya SK, Sharma R, Ali S. Down-regulated GFAPalpha: a major player in heavy metal induced astrocyte damage. Toxicol Mech Methods 2013; 23: 99-107.

(c) (i) (2) Cell Death and Disease is an open-access journal BY NC SA published by Nature Publishing Group. This work is licensed under a Creative Commons Attribution-NonCommercialShareAlike 3.0 Unported License. To view a copy of this license, visit http://creativecommons.org/licenses/by-nc-sa/3.0/

Supplementary Information accompanies this paper on Cell Death and Disease website (http://www.nature.com/cddis) 